\title{
Food Control
}

\section{Collaborative peer validation of a harmonized SPME-GC-MS method for analysis of selected volatile compounds in virgin olive oils \\ --Manuscript Draft--}

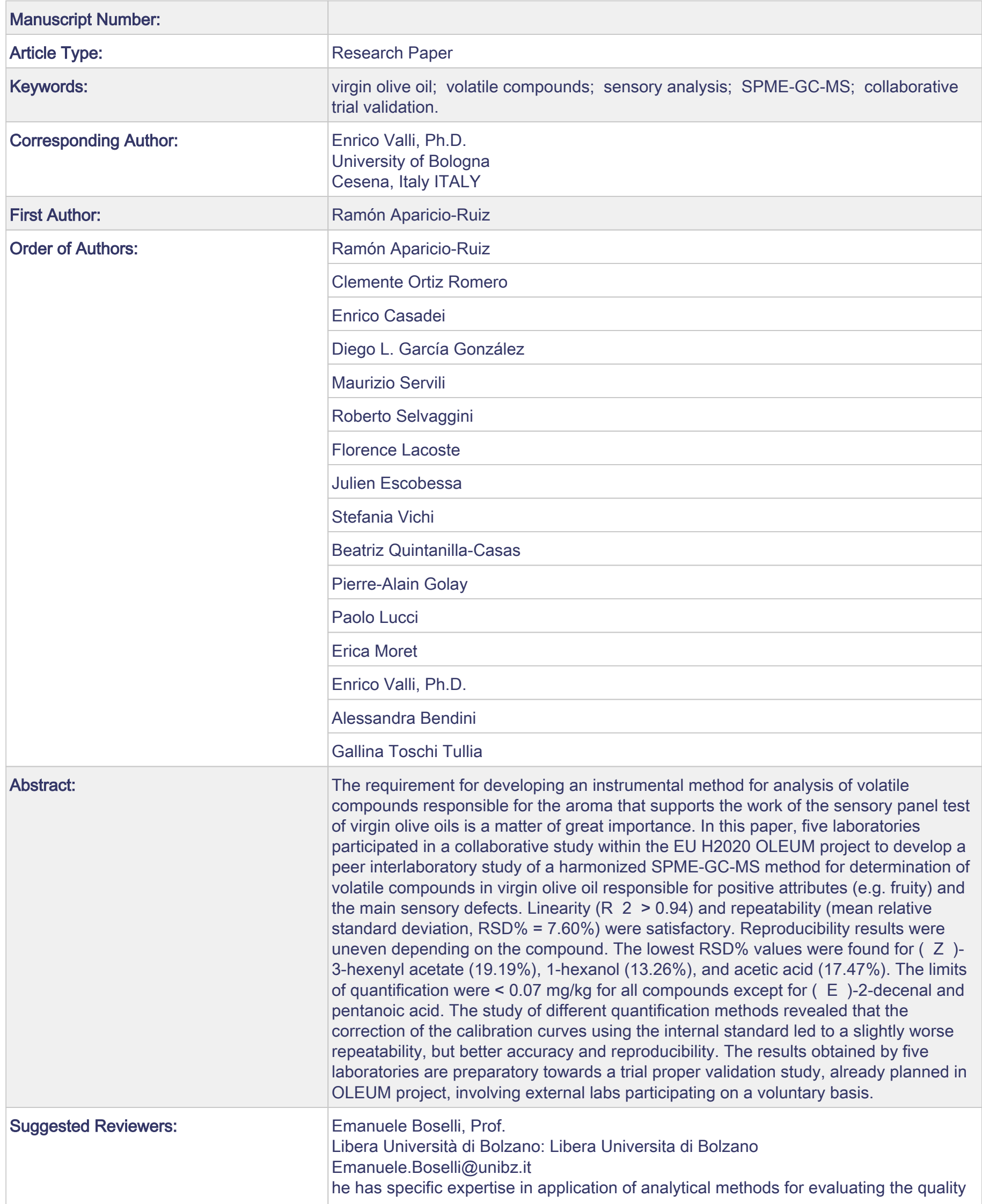


of fats and oils

Alegría Carrasco Pancorbo, Prof.

University of Granada: Universidad de Granada

alegriac@ugr.es

she has a deep knowledge on advanced analytical strategies used in edible oils

Zohar Kerem, Prof.

The Hebrew University of Jerusalem

zohar.kerem@mail.huji.ac.il

$\mathrm{He}$ is very knowledgeable in the current analytical problems of virgin olive oil quality control at world level. 


\section{Collaborative peer validation of a harmonized SPME-GC-MS method}

\section{for analysis of selected volatile compounds in virgin olive oils}

Ramón Aparicio-Ruiz ${ }^{1}$, Clemente Ortiz Romero ${ }^{1}$, Enrico Casadei $^{7}$, Diego L. García González ${ }^{1}$, Maurizio Servili ${ }^{2}$, Roberto Selvaggini ${ }^{2}$, Florence Lacoste ${ }^{3}$, Julien Escobessa ${ }^{3}$, Stefania Vichi ${ }^{4}$, Beatriz Quintanilla-Casas ${ }^{4}$, Pierre-Alain Golay ${ }^{5}$, Paolo Lucci $^{6}$, Erica Moret ${ }^{6}$, Enrico Valli ${ }^{7}$, Alessandra Bendini ${ }^{7}$, Tullia Gallina Toschi ${ }^{7}$ 1- Instituto de la Grasa (CSIC), Sevilla, Spain.

2 - Department of Agricultural, Food and Environmental Sciences, Università degli Studi di Perugia, Perugia, Italy.

3 - ITERG (Institut des Corps Gras), Canejan, France.

4 - Departament de Nutrició, Ciències de l'Alimentació i Gastronomia, Campus de l'Alimentació de Torribera, Universitat de Barcelona, Santa Coloma de Gramenet, Spain.

5 - Nestlé Research Center, Lausanne, Switzerland.

6 - Department of Agri-Food, Animal and Environmental Science Università degli Studi di Udine, Udine, Italy.

7- Department of Agricultural and Food Sciences, Alma Mater Studiorum - Università di Bologna, Cesena, Italy.

*Corresponding author: Dr. Enrico Valli, PhD. E-Mail: enrico.valli4@unibo.it; Tel: +39 0547

338116. Department of Agricultural and Food Sciences, Alma Mater Studiorum - Università di

Bologna, piazza Goidanich, 60, 47521 Cesena (FC), Italy. 


\section{Abstract}

The requirement for developing an instrumental method for analysis of volatile compounds responsible for the aroma that supports the work of the sensory panel test of virgin olive oils is a matter of great importance. In this paper, five laboratories participated in a collaborative study within the EU H2020 OLEUM project to develop a peer interlaboratory study of a harmonized SPME-GCMS method for determination of volatile compounds in virgin olive oil responsible for positive attributes (e.g. fruity) and the main sensory defects. Linearity $\left(\mathrm{R}^{2}>0.94\right)$ and repeatability (mean relative standard deviation, $\mathrm{RSD} \%=7.60 \%$ ) were satisfactory. Reproducibility results were uneven depending on the compound. The lowest RSD\% values were found for (Z)-3-hexenyl acetate (19.19\%), 1-hexanol (13.26\%), and acetic acid (17.47\%). The limits of quantification were $<0.07$ $\mathrm{mg} / \mathrm{kg}$ for all compounds except for $(E)$-2-decenal and pentanoic acid. The study of different quantification methods revealed that the correction of the calibration curves using the internal standard led to a slightly worse repeatability, but better accuracy and reproducibility. The results obtained by five laboratories are preparatory towards a trial proper validation study, already planned in OLEUM project, involving external labs participating on a voluntary basis.

Keywords: virgin olive oil; volatile compounds; sensory analysis; SPME-GC-MS; collaborative trial validation.

\section{Declaration of competing interest: None.}




\section{Introduction}

The analysis of volatile organic compounds (VOCs) has been identified as the best approach for supporting the current official method of sensory evaluation of positive and negative attributes (García-González et al., 2011; Morales et al., 2013; Cecchi et al., 2019; Valli et al., 2020; AparicioRuiz et al., 2019; Valli et al., 2020). Today, the evaluation of these attributes (presence/absence and their intensity) is carried out according to a method known as panel test (IOC, 1987 and subsequent amendments) which is the official method to classify virgin olive oils (VOOs) according to their aroma and organoleptic characteristics (EEC, 1991 and subsequent amendments). In fact, VOO is the only edible oil product with international regulations requiring official sensory analysis carried out by panelists to verify commercial categories (Garcia-Vico et al., 2017; García-González et al., 2018). However, the panel test is subject to some weaknesses and limitations (García-González \& Aparicio, 2004; García-González et al., 2007; Aparicio-Ruiz et al., 2019). Thus, debated classifications are sometimes observed as well as misalignments in the classification carried out by different panels (Barbieri et al., 2020a). These problems have promoted the investigation of instrumental tools to support the daily work of panelists and to overcome other known drawbacks, such as the length and cost of the sensory analysis procedure and the limited number of panels (Aparicio-Ruiz et al., 2019; Romero et al., 2015; Casadei et al., 2021) in addition to the recommendations for managing a panel in emergency circumstances, such as a pandemic (IOC, 2020). To mitigate these drawbacks, an instrumental method based on the analysis of VOCs is required with the objective of providing additional analytical information to reinforce VOO classification into quality categories. These methods can be based on untargeted approaches with the aid of chemometric classification (GarcíaGonzález \& Aparicio, 2004; Quintanilla-Casas et al., 2020; Garrido-Delgado et al. 2011, Valli et al., 2020; Barbieri et al., 2020b) or targeted determination of individual volatile markers as they are key odorants of VOO aroma (Aparicio et al., 2012; Morales et al., 2013; Servili et al., 2015; Cecchi et al., 2019; Casadei et al., 2021). In the targeted determination, prior to proposing a classification scheme 
based on concentration ranges or decision rules, it is necessary to evaluate the performance of the method in quantitative terms with an interlaboratory perspective. Thus, in addition to intra-lab validation studies (Romero et al., 2015; Aparicio-Ruiz et al., 2018; Cecchi et al., 2019), the aim is to propose a daily routine method that is focused on detection of a minimum number of selected diagnostic markers. Moreover, an inter-lab study was also carried out to check the results when slightly different conditions are applied (e.g. different column brands, different GC instrument and equipment).

Although several analytical solutions have been proposed for VOO quality control, to date the regulatory bodies are unwilling to adopt them, partially due to the lack of a harmonized protocol that is accepted and internationally applied and the lack of inter-lab performance evaluation. One of the main sources of variability in the methods is the extraction technique to concentrate volatile compounds (Morales et al., 2013). In the last years, methods based on SPME are gaining importance in relation to other approaches because of their simplicity and efficiency in extraction, not only in VOO analysis (Vichi et al., 2003; Morales 2013), but also in the quality control of other foods (Giuffrida et al., 2005; Jimenez-Alvarez et al., 2008a, 2008b). Kanavouras et al. (Kanavouras, Kiritsakis \& Hernandez, 2005; Kanavouras \& Hernandez, 2006) compared the isolation capability between Tenax trapping and HS-SPME. They observed that a larger amount of volatile compounds was isolated when applying the first technique, while the second was quicker and led to a more rapid descriptive analysis of oxidized VOOs. On the other hand, Servili et al. (2004) compared the HeadSpace Analysis (HSA) of volatile compounds in olive oils using SPME-GC/MS, electronic nose and Proton Transfer Reaction (PTR)-MS in terms of their capacity to classify VOOs according to the variety, geographical origin and ripening stage of the fruit.

Another source of variability in the analytical methods is the detector. In this regard, recently, another comparative study was carried out on two SPME-GC methods: SPME-GC-mass spectrometry (MS) and SPME-GC-Flame Ionization Detector (FID) (Aparicio-Ruiz et al., 2018). The 
results and the experience working with both detectors highlighted that the two options provide advantages, and thus it is necessary to evaluate the performance of methods based on the two detectors. FID is a robust and low-cost option, and commonly used in all the labs working on quality control of VOO. On the other hand, MS facilitates the identification of volatile compounds, which is particularly advantageous in VOO aroma given the presence of a large number of volatile compounds (Morales et al., 2013; Cecchi et al., 2021). With the aim of developing analytical instrumental methods to support the panel test, the European Union has encouraged the development, harmonization and validation of such methods through the Horizon 2020 funded project OLEUM (Casadei et al., 2021). Within the frame of this project, a harmonized method with two possible detectors has been developed (SPME-GC-FID and SPME-GC-MS) to analyze volatile compounds in VOOs. The harmonization includes the definition and set up of all the possible variables that were identified as sources of errors, such as GC column, SPME fiber composition and length, vial volume, and internal standard, as well as the calibration and quantification procedures (Casadei et al., 2021). The performance of the method based on SPME-GC-FID has been evaluated in a peer interlaboratory study by three different laboratories involved in the OLEUM project (Casadei et al., 2021). With the same objective, in the present work, five laboratories, all being active partners in the OLEUM project, carried out an inter-lab evaluation of the SPME-GC-MS joint protocol. The validation was carried out by each laboratory following the same analytical conditions and on the same samples, in order to make the results obtained by each laboratory comparable in a harmonized procedure and methodology, as previously done with FID (Casadei et al., 2021). Aside from the detector, the analytical variables are the same as those used in SPME-GC-FID, as well as the analyzed samples and the time frame given to the labs to provide their data. For these reasons, the outcomes of this work are also comparable with the results obtained by Casadei et al. (Casadei et al., 2021). Although the primary objective of this investigation is not to compare the results from SPME-GC-FID and SPME-GC-MS, some conclusions comparing the analytical parameters will be provided. 


\section{Materials and Methods}

118

\subsection{Chemicals}

Table 1 shows the VOCs studied in this work. The pure standards of these compounds were purchased from Merck KGaA (Darmstadt, Germany). The CAS number and purity of each of the standards are also shown in Table 1 . Additionally, a mixture of $n$-alkanes from 8 to 20 carbon atoms ( $40 \mathrm{mg} / \mathrm{L}$ each, in $n$-hexane) and 4-methyl-2-butanol (purity $\geq 98 \%$ ) were also purchased from the same supplier for calculation of the linear retention indexes (LRI) and its use as internal standard (IS), respectively.

\subsection{Samples}

For this study, a set of 15 samples were selected for the peer inter-laboratory validation study of the SPME-GC-MS method. The selection was carried out to possibly cover the natural ranges of concentration normally present in VOOs and were the same samples used in a previous study on SPME-GC-FID performance (Casadei et al., 2021). These samples were sensory evaluated in the course of the OLEUM project by six panels (Barbieri et al., 2020a) to have accurate information on their commercial categories. Thus, these samples were categorized as 3 extra virgin (EV), 6 virgin (V), and 6 lampante (L) olive oils. In Vs and Ls, 6 oils were graded as rancid, 3 as fusty/muddy sediment, 2 as musty-humid-earthy and 1 as winey-vinegary according to the main perceived defect reported by the panelists.

\subsection{Internal standard (IS) solution and sample preparation}

The IS solution was prepared as described by Casadei et al. (2021). For this purpose, 4-methyl2-pentanol, the IS used in this work, was diluted in refined oil to have an approximate concentration of $50 \mathrm{mg} / \mathrm{kg}$. The weights during this preparation were used to calculate the exact concentration. The sample was also prepared following the procedure by Casadei et al. (2021) in which $0.1 \mathrm{~g}$ of the IS 
solution was added to $1.9 \mathrm{~g}$ of the VOO sample to have an approximate concentration of $2.5 \mathrm{mg} / \mathrm{kg}$. The exact concentration was also calculated by considering the weights in the preparation.

\subsection{Gas chromatographic coupled to mass spectrometer analysis}

The sample, placed in a $20 \mathrm{~mL}$ vial closed with a septum (polytetrafluoroethylene), was left for $10 \mathrm{~min}$ at $40^{\circ} \mathrm{C}$ under agitation to allow for equilibration of the volatiles in the headspace. After that, the SPME fiber was exposed to the headspace for $40 \mathrm{~min}$ at $40{ }^{\circ} \mathrm{C}$. The fiber was then inserted into the injector port of the GC. Table 2 describes the specific characteristics of the analysis carried out by the five labs that applied the joint protocol: University of Udine, University of Perugia, ITERG, University of Barcelona, and Nestlé Research Center, coded as Laboratory 1-5 respectively. The volatiles adsorbed by the fiber were thermally desorbed in the hot injection port of a GC for 5 min at $250{ }^{\circ} \mathrm{C}$ with the purge valve off (splitless mode) and injected into a capillary column of a gas chromatograph with a mass spectrometry detector. The capillary column was of a polar phase based on polyethylene glycol (PEG) (e.g. ZB-WAX or TR-WAX), length $60 \mathrm{~m}$, internal diameter $0.25 \mathrm{~mm}$ and coating $0.25-0.50 \mu \mathrm{m}$. The specific column brand and characteristics of each lab are shown in Table 2. The transfer line temperature was set at $260{ }^{\circ} \mathrm{C}$. The temperature of the ion source was set according to the technical specifications of each instrument. The carrier gas used by the five labs was helium, although this parameter was not specified in the harmonized protocol. The oven temperature was held at $40{ }^{\circ} \mathrm{C}$ for $10 \mathrm{~min}$ and then programmed to increase by $3{ }^{\circ} \mathrm{C} / \mathrm{min}$ to a final temperature of $200{ }^{\circ} \mathrm{C}$. A cleaning step was added at the end of the oven programmed temperature by all participants (20 ${ }^{\circ} \mathrm{C} / \mathrm{min}$ to $250{ }^{\circ} \mathrm{C}$ for $5 \mathrm{~min}$ ) to ensure that the column was ready for the next analysis.

\subsection{Identification and quantification of VOCs}

Linear Retention Index (LRI) and standards were used for identification (Casadei et al., 2021) in addition to mass spectrometry (MS databases of each lab shown in Table 2). Table 1 shows the characteristic $\mathrm{m} / \mathrm{z}$ of each compound to be used in the integration with the extracted ion 
chromatogram mode. The positive ionization mode was used in the 5 labs. Figure 1 shows the chromatogram of L and V samples.

The quantification of selected VOCs was carried out by the three quantification methods described by Casadei et al. (2021), named QM1, QM2, and QM3. These three methods were applied by the five labs using the same Excel files for the calculations. QM1 and QM2 used the calibration curves with the equations $\mathrm{A}_{\text {Analyte }} / \mathrm{A}_{\mathrm{IS}}=\mathrm{m}_{\mathrm{QM} 1} \cdot \mathrm{C}_{\text {Analyte }}$ and $\mathrm{A}_{\text {Analyte }}=\mathrm{m}_{\mathrm{QM} 2} \cdot \mathrm{C}_{\text {Analyte}}$, respectively; where $\mathrm{A}_{\text {Analyte }}$ is the area corresponding to the analyte, $\mathrm{A}_{\text {IS }}$ is the area corresponding to the IS used in building the calibration curves and $\mathrm{m}_{\mathrm{QM} 1}$ is the slope of the calibration curve. QM3 was based in the equation $\left(\mathrm{A}_{\text {Analyte }} / \mathrm{A}_{\mathrm{IS}}\right)=\left(\mathrm{m}_{\text {Analyte }} / \mathrm{m}_{\mathrm{IS}}\right) \cdot\left(\mathrm{C}_{\text {Analyte }} / \mathrm{C}_{\mathrm{IS}}\right)$; where $\mathrm{A}_{\text {Analyte }}$ is the area corresponding to the analyte, $\mathrm{A}_{I S}$ is the area corresponding to the IS, $\mathrm{m}_{\mathrm{IS}}$ is the slope of the calibration curve built for IS, $\mathrm{m}_{\text {Analyte }}$ is the slope of the calibration curve built for the analyte, $\mathrm{C}_{\text {Analyte }}$ is the concentration corresponding to the analyte, and $\mathrm{C}_{\text {IS }}$ is the concentration of the IS in the sample (Kalua, Bedgood, \& Prenzler, 2006).

\subsection{Calibration curves}

The quantification of the selected VOCs in the headspace of VOOs was carried out by using calibration curves that were built as linear regression (intercept equal to 0), for the 18 VOCs described in Table 1. These calibration curves were prepared using standard mixtures (SMs), as reported in Casadei et al., 2021 (Casadei et al., 2021), instead of preparing dilutions for each single compound. The two mixtures, coded as SM-A and SM-B (Table 1), were prepared to have a concentration of $10,000 \mathrm{mg} / \mathrm{kg}$ for each VOCs, and were used to have subsequent dilutions, coded as SM1 (200 $\mathrm{mg} / \mathrm{kg}), \mathrm{SM} 2(20 \mathrm{mg} / \mathrm{kg})$ and SM3 (2 mg/kg). SM1 was prepared by adding $5 \mathrm{~g}$ of refined olive oil in a $20 \mathrm{~mL}$ vial. Next, $0.2 \mathrm{~g}$ of SM-A or SM-B was added and more refined olive oil was added to reach a total of $10 \mathrm{~g}$. In order to prepare SM2, $1 \mathrm{~g}$ of SM1 was added to $5 \mathrm{~g}$ of refined olive oil. SM3 was likewise prepared by adding $1 \mathrm{~g}$ of SM2 to $5 \mathrm{~g}$ refined olive oil. The necessary weights of refined oil and these three standard mixtures to obtain these concentrations are described by Casadei et al. 
The concentrations used for calibration curves were $0.05,0.10,0.15,0.20,0.25,0.5,1.00$,

$1.50,2.00,2.50,5.00$, and $10.00 \mathrm{mg} / \mathrm{kg}$ for the compounds included in SM-A. The calibration curves for the compounds in SM-B were the same but adding three new points $(15.00,20.00$, and 25.00 $\mathrm{mg} / \mathrm{kg}$ ), since most of these compounds were present in VOO at higher concentration.

\subsection{Peer inter-laboratory validation of the method}

The parameters considered were those in accordance with ISO 78-2 and ISO 5725 (ISO, 2016, 2019): repeatability, reproducibility, linearity, recovery, precision, limits of detection (LOD) and quantification (LOQ), which were compared in order to have a peer inter-laboratory validation of the method. This study was carried out for each of the 18 quantified VOCs.

\subsubsection{Linearity}

Linearity was evaluated using the calibration curve for each VOC (section 2.7). The regression coefficient $\left(\mathrm{R}^{2}\right)$ was considered for each calibration curve, built as linear regression passing through the origin of the axes.

\subsubsection{Repeatability}

The repeatability of the method was studied in terms of intra-day precision with a single operator and instrument in each of the laboratories. With this purpose, one L sample (with rancid as main perceived defect) selected from the 15 samples was analyzed seven times in a single batch; the relative standard deviation (RSD\%) was calculated for each of the 18 analytes.

\subsubsection{Reproducibility}

For reproducibility, the study was based on the analysis of the 15 samples. These samples were analyzed in duplicate by the five laboratories. The relative standard deviation of the concentrations provided by the involved labs was calculated. 
Recovery was calculated by analyzing the two standard mixtures, SM-A and SM-B, diluted in refined olive oil to reach $5 \mathrm{mg} / \mathrm{kg}$. For each of the 18 analytes, the following formula was applied:

$$
R_{a p}=\frac{C}{\mathrm{C}_{\text {ref }}} \times 100
$$

Where $\mathrm{R}_{\mathrm{ap}}$ was the apparent recovery, $\mathrm{C}$ is the concentration determined with QM1, QM2 or

QM3 (see section 2.6), and $\mathrm{C}_{\text {ref }}$ is the actual concentration calculated from the exact weights in the dilution of SM-A and SM-B to reach the target concentration of $5 \mathrm{mg} / \mathrm{kg}$.

\subsubsection{Precision associated with the internal standard}

To calculate the precision associated with the IS, the relative standard deviation (RSD) of the chromatographic area of the IS (4-methyl-2-pentanol) determined in the repeatability study (see section 2.7.2) was used. In fact, the precision should not only consider variability in the instrumental measurement, but also in the addition of the IS. The precision (RSD\% Area IS) was calculated using the formula:

$$
R S D \%_{\text {Area IS }}=\frac{\delta_{\text {Area IS }}}{\overline{\mathrm{X}}_{\text {Area IS }}} \times 100
$$

226 Where $\delta_{\text {Area IS }}$ is the standard deviation of the chromatographic areas assigned to the IS and $\overline{\mathrm{X}}_{\text {Area IS }}$ 227 is the average of these areas.

LOD was defined as the minimum amount or concentration of each compound that can be reliably detected. Since several procedures to calculate LOD and LOQ are available in the literature, in this investigation different calculation methods were applied, all being based on the slope of the 
233 (Desimoni \& Brunetti, 2015; Shrivastava \& Gupta, 2011) through the following equations 234 (henceforth, calculation methods 1-4):

235 1) $\mathrm{LOD}=3.3 \times\left(\mathrm{SE}_{\text {regression }} / \mathrm{m}_{\mathrm{QM} 1}\right)$, using the ratio Area $\mathrm{Analyte}_{\text {Area }}$ as as the variable $\mathrm{Y}$ of the regression 236 and where SE is the standard error of the regression.

237 2) $\mathrm{LOD}=3.3 \times\left(\mathrm{SE}_{\text {intercept }} / \mathrm{m}\right)$, using the ratio Area Analyte/Areais as the variable $\mathrm{Y}$ of the regression with 238 intercept different from zero.

$2393) \mathrm{LOD}=3.3 \times\left(\mathrm{SE}_{\text {intercept }} / \mathrm{m}\right)$, using the Area Analyte as the variable $\mathrm{Y}$ of the regression with intercept 240 different from zero.

241 These three methods were applied in the five laboratories to extract the LODs. Additionally, a fourth method (henceforth calculation method 4) based on the following equation was applied:

4) $\mathrm{LOD}=3.3 \times\left(\delta_{\mathrm{Areas}} / \mathrm{m}_{\mathrm{QM} 1}\right)$, where $\delta_{\text {Areas }}$ (standard deviation) is referred to three replicated areas at 244 low concentration $(0.05 \mathrm{mg} / \mathrm{kg})$.

\subsubsection{Limits of determination or quantification ( $L O Q s)$}

LOQ was calculated through the same calculation methods applied for LOD, but applying a factor of 10 instead of 3.3, both based on the calibration curves (see methods 1-4 listed in the section 2.7.6) and the additional calculation of $\mathrm{S} / \mathrm{N}$. In the latter, a $\mathrm{S} / \mathrm{N}$ of 10 is generally accepted to be 249 sufficient to allow for quantification of the analyte. 1950). Analysis of variance ( $\mathrm{p}<0.05)$ was carried out with Statistica (StatSoft Inc., Tulsa, OK).

\section{Results and Discussion}


The performance of the method was assessed through evaluation of several parameters

(Aparicio-Ruiz et al., 2021), as explained in the following paragraphs. Moreover, a discussion was carried out that focused on comparison of results with those related to the parallel SPME-GC-FID approach (Casadei et al., 2021) with the view to evaluate the advantages, disadvantages and/or opportunities offered by the two detectors.

In assessment of these parameters, data obtained by the laboratories were reported in an Excel file to avoid errors and ensure that they were computed using the same procedure.

\subsection{Linearity}

Linearity was studied for the two types of calibration curves described in section 2.7 (QM1 and QM2). The study of regression performance (mainly $\mathrm{R}^{2}$ coefficient and typical error) for these two quantification strategies allowed assessment of the effect of the IS in linearity, since both quantification methods differs in the use of the IS to correct the calibration curves. Table 3 shows the mean values of the $\mathrm{R}^{2}$ for the 18 volatile compounds reported by the five labs. $\mathrm{R}^{2}$ coefficients were higher than 0.94 for the 18 selected volatile compounds. The coefficients provided by the labs were homogeneous and no large differences between them were detected. Thus, the standard deviations of $\mathrm{R}^{2}$ for the five labs had a maximum of 0.058 and 0.072 for QM1 and QM2 respectively. The $\mathrm{R}^{2}$ data were significantly higher ( $\mathrm{p}>0.05$ ) for QM1 for ethyl acetate, ethanol, ethyl propanoate, 3-methyl-1butanol, while $\mathrm{R}^{2}$ were higher for QM2 in the case of (E)-2-heptenal, 6-methyl-5-hepten-2-one, nonanal, $(E, E)-2,4$-hexadienal, and pentanoic acid. However, the effect of the IS was more evident in the improvement of linearity in QM1 for the aforementioned compounds. Figure S1 shows the calibration curves of ethyl propanoate and $(E, E)$-2,4-hexadienal as examples of two compounds in which the IS had an evident effect on linearity. Although these are two extreme cases that were not seen in all the labs and the effect of IS on linearity was not always so obvious, the mean $\mathrm{R}^{2}$ (Table 3 ) showed a clear effect of linearity for these two compounds. Thus, in the case of ethyl propanoate, the correction by the IS (QM1) produced a better linearity ( $\mathrm{R}^{2}$ for QM1 and QM2 were 0.994 and 0.939 , 
respectively), while in the case of $(E, E)-2,4$-hexadienal, better linearity was obtained when the calibration was made without the correction applied by the IS ( $\mathrm{R}^{2}$ for QM1 and QM2 were 0.975 and 0.997, respectively).

The compound that provided the worst linearity in terms of $\mathrm{R}^{2}$ was $(E)$-2-decenal $\left(\mathrm{R}^{2}\right.$ for $\mathrm{QM} 1$ and QM2 were 0.942 and 0.966$)$. On the other hand, the best linearity $\left(\mathrm{R}^{2}>0.990\right)$ was observed for (E)-2-hexenal, acetic acid, 1-hexanol, ethyl propanoate, hexanal, octane, and 3-methyl-1-butanol.

The typical errors and slopes of each compound were also studied in the case of QM1, where the concentration is calibrated against the ratio of AreaAnalyte/Areass, and the latter ratio allows comparison between labs and instruments. The slopes for each compound are shown in Table S2 and Figure S2. The slope was particularly high for ethyl acetate and ethyl propanoate, with a mean slope of 0.666 and 0.508 , respectively (Table S2). However, the standard deviation of these mean slopes ( 0.655 and 0.552 for ethyl acetate and ethyl propanoate, respectively) demonstrates the wide variety between labs. Thus, for example, Figure 2 shows the calibration curves of the five labs for ethyl propanoate. The different slopes can indicate the different sensitivities of the MS detector for this compound. Excluding octane, ethanol and acetic acid, for the remainder of the compounds, the slope values were lower than 0.1 (Table S2). In terms of typical error, the highest mean errors were found for ethyl acetate and ethanol (0.231 and 0.184 , respectively), with also a large difference between labs.

\subsection{Repeatability}

The repeatability of the method was studied for each of the compounds quantified by each one of the three quantification methods (QM1, QM2 and QM3). Table 4 shows the repeatability expressed as mean RSD\%. Considering the results for QM1, the volatile compounds with RSD\% higher than $10 \%$ were ethyl propanoate, nonanal, and (E)-2-decenal. The RSD\% value for the latter compound was particularly high $(17.23 \%)$, probably due to the low concentration in the sample studied $(0.002$ $\mathrm{mg} / \mathrm{kg}$ ). The average RSD\% for the 18 compounds was $7.60 \%$, although it was $6.16 \%$ when the three 
aforementioned compounds were omitted. Regarding the other two quantification methods, QM2 and QM3, the RSD\% values were generally lower compared with QM1. However, significant differences were found only for the acids (acetic, propanoic and pentanoic acids) between the RSD\% values from QM1 and QM2, in (Z)-3-hexenyl acetate and (E)-2-decenal between the RSD\% values from QM1 and QM3, and in the (Z)-3-hexenyl acetate and 1-hexanol between the RSD\% values from QM2 and QM3 (Table 4).

The RSD\% values of the duplicates of the 15 VOOs were also examined to check if the repeatability RSD\% shown in Table 4 agreed with the variability observed in the duplicates, considering that the 15 samples included a wide range of qualities and concentration values. These RSD\% values are shown in Figure S3. The highest RSD\% values corresponded to ethyl propanoate $(8.38 \pm 7.58 \%)$, nonanal $(14.18 \pm 13.82 \%), 1$-octen-3-ol $(11.20 \pm 10.36 \%),(E, E)-2,4$-hexadienal $(9.71 \pm 8.55 \%),(E)-2$-decenal $(10.83 \pm 8.31 \%)$, and pentanoic acid $(12.32 \pm 11.85 \%)$. These results confirmed the lower repeatability for ethyl propanoate, nonanal and (E)-2-decenal.

\subsection{Reproducibility}

The reproducibility was studied by analyzing 15 samples in duplicate by each lab, including the three quality categories. Table 5 shows the mean RSD\% for each VOC for the first quantification method (QM1). The concentration ranges determined by the labs for each sample are also shown in Table 5. Outliers were removed by Grubbs' test (alpha $=0.05)$. The higher RSD\% values $(>40 \%)$ corresponded to 6-methyl-5-hepten-2-one (43.20\%), nonanal (46.05\%), and (E,E)-2,4-hexadienal $(63.46 \%)$. Octane $(38.50 \%)$ and ethyl propanoate $(38.96 \%)$ also showed RSD\% close to $40 \%$. In the case of ethyl propanoate, these values can be explained by the low concentration values $(<0.05$ in most cases). The lowest RSD\% values (<20\%) were found for (Z)-3-hexenyl acetate (19.19\%), 1 hexanol (13.26\%), and acetic acid (17.47\%). Table 5 shows the RSD\% values when the quantification methods QM2 and QM3 were applied. The RSD\% values for QM1 were generally lower compared with those found for QM2 and QM3. Thus, RSD\% average values for the 18 compounds were 
$30.89 \%, 48.02 \%$ and $55.41 \%$. The comparison of RSD\% values for QM1 and QM2 revealed a correction effect of the IS when results from different labs are compared, while the intra-lab repeatability RSD\% was similar or lower for QM2 in which no IS correction was applied (Table 5).

The reproducibility RSD\% values of QM1 were significantly lower $(\mathrm{p}<0.05)$ than the values obtained with QM2 for 10 of the 18 compounds: octane, ethyl acetate, 3-methyl-1-butanol, (E)-2-hexenal, (Z)3-hexenyl acetate, (E)-2-heptenal, 6-methyl-5-hepten-2-one, 1-hexanol, propanoic acid, and pentanoic acid (Table 5). Regarding QM3, the RSD\% values were also significantly higher than those obtained with QM1 for 8 compounds. These results highlight that QM1 was the best method in terms of reproducibility. However, recovery (section 3.4), among other parameters, is also another important criterion to be considered.

\subsection{Recovery}

Table 6 shows the mean recovery values $(\%)$ for each of the selected volatile compounds obtained with the three quantification methods (QM1, QM2, and QM3). The recovery values derived from the ratio of the actual concentrations, obtained considering the exact weights in the dilution of SM-A and SM-B to reach the target concentration $(5 \mathrm{mg} / \mathrm{kg})$, with the calculated ones determined with the three quantification methods. The mean recovery values were $94 \%, 105 \%$ and $179 \%$ for QM1, QM2, and QM3, respectively. These results are comparable with the same values obtained in a parallel peer inter-laboratory validation work carried out with FID detector and three labs: 89\%, $115 \%$, and $181 \%$ for QM1, QM2, and QM3, respectively (Casadei et al., 2021). From the three quantification methods, QM1 provided the best recovery (close to 100\%) among the three calculation methods, followed by QM2. Thus, the mean recovery values ranged from $72 \%$ to $106 \%$ for QM1 while they ranged from $71 \%$ to $150 \%$ for QM2. In another work, a method based on dynamic headspace thermal desorption (DHS-TD) combined to GC-MS was developed to identify and simultaneously quantify 51 VOCs in EVs and the recoveries obtained ranged from $50.9 \%$ to $113.9 \%$ (Reboredo-Rodríguez et al., 2012). However, this study was carried out with a different sampling and therefore the recovery values are not fully comparable (Oliver-Pozo et al, 2019). Following the 
analysis of the results in the present study, QM2 showed better results for nonanal and acetic acid compared to QM1. These results point out that the IS exerted a negative effect by introducing more error in the quantification for these two compounds, while the use of IS reduced quantification errors in terms of accuracy in the remainder of the compounds. Nevertheless, a dependent analysis of variance $(\mathrm{p}<0.05)$ showed that there were no significant differences between the recovery values obtained with QM1 and QM2. In the case of QM3, a significant difference with respect to QM1 was observed for $(E)$-2-decenal. Furthermore, the high standard deviation for the recovery values obtained for QM3 for all the compounds points out the higher variation of the values between labs when this quantification methodology is applied. Thus, the standard deviation varied between 5-67\% for QM1, $11-80 \%$ for QM2, and 29-221\% for QM3.

Analyzing the differences between compounds, and focusing on recovery values for QM1, the highest errors (difference of recovery values with respect to 100\%) in quantification were observed for (E)-2-hexenal, (Z)-3-hexenyl acetate, 1-octen-3-ol, acetic acid, and nonanal and (E)-2-decenal, which were particularly noticeable in the latter compound. Thus, the deviation of $100 \%$ recovery in this compound was around $28 \%$ (Table 6), while in the other 5 compounds this error was always below $20 \%$. With respect to the other compounds, the deviation from $\mathrm{R}_{\mathrm{ap}}=100 \%$ was always lower than $10 \%$. Only ethanol, ethyl propanoate, hexanal, (E)-2-heptenal, and 6-methyl-5-hepten-2-one were affected by a slight overestimation $\left(\mathrm{R}_{\mathrm{ap}}>100 \%\right)$, while the remainder were affected by underestimation $\left(\mathrm{R}_{\mathrm{ap}}<100 \%\right)$.

In general, the different recoveries obtained for the selected compounds can be partially explained by a low or higher adsorption on the fiber and by competition phenomena with other compounds that have a higher affinity for the fiber polymers (Oliver-Pozo, Aparicio-Ruiz, Romero, \& García-González, 2015). These phenomena may influence the linearity of the calibration curves, especially when the compounds are present at high concentrations. With the aim of evaluating the impact on quantification of the possible lack of linearity at the points of high concentrations $(>10$ 
$\mathrm{mg} / \mathrm{kg})$, the analytes were quantified again using a calibration curve at low concentrations $(0.05-2.5$ $\mathrm{mg} / \mathrm{kg}$ ) and the recovery values were compared when the entire concentration range was used in the calibration $(0.05-10.00 / 25.00 \mathrm{mg} / \mathrm{kg})$ (Table 6). In the case of the recovery values calculated from QM3, no significant differences were observed when comparing the recoveries obtained from the two concentration ranges. The lack of a significant difference may be partially explained by the high variation of recovery values for QM3 between the 5 labs. This variation was shown by the standard deviation found for QM3 recoveries, which was higher compared with those for QM1 and QM2 (Table 6). On the contrary, in the case of QM1, significantly different recovery values were obtained for ethyl acetate and (E)-2-decenal, whereas significant differences were found for octane, ethyl acetate, ethyl propanoate, propanoic acid and (E)-2-decenal for QM2. Regarding the mean of the mean recovery values, they were $94.23 \%$ and $129.80 \%$ for QM1 when the entire concentration range and the low concentration range were used respectively. These two values were $105.04 \%$ and $100.99 \%$ for QM2 and $179.29 \%$ and $176.26 \%$ for QM3. These results show that the calibration with lower concentrations did not produce better results in general terms since significant differences were found for only some compounds.

\subsection{Precision associated with the IS}

Since the IS influences quantification, the RSD\% of the chromatographic areas corresponding the IS was studied for each of the participant labs by analyzing the 15 samples for the reproducibility study ( $\mathrm{N}=15$ for each lab). The RSD\% ranged from $4.02 \%$ to $15.44 \%$ for the five labs, the mean RSD $\%$ being $9.66 \%$. This error could be attributed to instrumental error or to competition phenomena in the absorption to the SPME fiber rather than to the human error by adding $0.1 \mathrm{~g}$ of the IS solution to the sample. A study made by adding $0.1 \mathrm{~g}$ of this solution by one operator for 60 times $(\mathrm{N}=60)$ revealed a RSD\% value in the measured weights of only $0.66 \%$. The lowest values of the IS chromatographic areas corresponded to L and $\mathrm{V}$ olive oils category in which high intensity of defects were identified and consequently the higher concentration of compounds can produce competition phenomena 
(Oliver-Pozo et al., 2015). Thus, two samples coded as S5 and S15 (Table 5) were characterized with significantly lower values of IS chromatographic areas, and these two samples were two L oils with a high median of defect (5.2 and 5.4, respectively, for fusty/muddy sediment defect). Without these two samples, the average RSD\% was $7.15 \%$ (ranging from $4.06 \%$ to $11.46 \%$ ).

\subsection{Limits of detection (LOD)}

Three methodologies were studied to obtain the limits of detection in the calibration curves built by each of the VOCs. The first method (calculation method 1, section 2.7.6) used standard error of the regression and the calibration equations having an intercept forced to zero. The other two methods, referred to as calculation methods 2 and 3, used calibration equations having an intercept, and the standard deviation of this intercept was used in the calculation of the LOD. Method 2 used the chromatographic area of the analyte divided by the area of the IS as instrument output, while method 3 used the chromatographic area of the analyte. The objective of applying different methods was to check the consistency of the LOD obtained through different procedures and to check which results best matched with the actual observations of the signals at low concentrations (Aparicio-Ruiz et al., 2018). The LOD values calculated with these methods are shown in Table 7 as means and ranges of the values obtained from the laboratories involved. The values were $>0.10 \mathrm{mg} / \mathrm{kg}$ for all compounds. Method 1 produced higher values than methods 2 and 3. Thus, the LOD obtained from calculation method 2 ranged from 0.10 to $0.59 \mathrm{mg} / \mathrm{kg}$, while the LODs from method 1 were higher than $1.00 \mathrm{mg} / \mathrm{kg}$ for 9 compounds.

The highest values of LODs in the three methods were found for hexanal, 1-hexanol, 1-octen3-ol, (E,E)-2,4-hexadienal, acetic acid, and (E)-2-decenal (e.g. > $1.5 \mathrm{mg} / \mathrm{kg}$ for calculation method 1). The lowest values were found for octane, ethyl acetate, ethyl propanoate, 3-methyl-1-butanol, and propanoic acid (e.g. $<0.65 \mathrm{mg} / \mathrm{kg}$ for calculation method 1). However, it was observed that concentrations which were lower than the calculated LODs produced clearly detectable signals as observable peaks in the chromatogram with measurable chromatographic areas. Thus, the LOD 
values obtained with these methods did not match the perceived signals when analyzing compounds in the low concentration range of the calibration curve $(0.05-0.25 \mathrm{mg} / \mathrm{kg})$. In the low concentrations, the signals were always detected and linearity was observed. Table S3 shows the regression coefficients $\left(\mathrm{R}^{2}\right)$ when low concentrations were considered $(0.05,0.10,0.15,0.20,0.25 \mathrm{mg} / \mathrm{kg})$. All compounds showed $\mathrm{R}^{2}$ values $>0.90$ in this range of the calibration, except for nonanal and $(E)-2$ decenal $(0.613$ and 0.629 , respectively), since they were barely detected at low concentration $(0.05$ $\mathrm{mg} / \mathrm{kg}$ ) by three of the five laboratories. On the contrary, two labs obtained $\mathrm{R}^{2}$ values $>0.95$ for these two compounds. In addition, the calculated standard deviation of the $\mathrm{R}^{2}$ presented low values, being $<0.11$ for all the compounds except nonanal and $(E)-2$-decenal ( 0.436 and 0.431 , respectively). These results show that the response of the detector for nonanal and $(E)$-2-decenal may differ depending on the characteristics of the mass detector. The low LODs in these two compounds is also affected by the low adsorption to the SPME fiber compared with other compounds. Thus, Figure S4 shows the chromatograms of SMA and SMB (Table 2) diluted at a concentration of $20 \mathrm{mg} / \mathrm{kg}$. Nonanal and $(E)$ 2-decenal showed a chromatographic area that were 10 times lower than the other compounds. Table S3 also shows the values of the slope and intercept when a regression equation is built with the low concentration range. The mean values of the slope ranged from 0.001 to 0.959 , which shows a different sensitivity of the detector depending on the compounds. On the other hand, the intercept values were close to zero in all cases, ranging from -0.033 to 0.014 , pointing out a lack of impurities or noise.

The results described above illustrate the need to calculate LOD values that are in accordance with observations when the analytes are analyzed at low concentrations. Thus, an additional method (calculation method 4) based on the standard deviation of the areas for three replicates of the analyses of the analytes at low concentration $(0.05 \mathrm{mg} / \mathrm{kg})$ was applied. This methodology provided more representative values when it was applied in the peer validation study for SPME-GC-FID method (Casadei et al., 2021). The LOD values were in the range $0.01-0.18 \mathrm{mg} / \mathrm{kg}$. The lowest LODs $(0.01$ 
$\mathrm{mg} / \mathrm{kg}$ ) corresponded to octane, 3-methyl-1-butanol, (E)-2-hexenal, (Z)-3-hexenyl acetate, 1-hexanol, 1-octen-3-ol, (E,E)-2,4-hexadienal, acetic acid, and propanoic acid, while the highest LOD (0.18 $\mathrm{mg} / \mathrm{kg}$ ) corresponded to $(E)$-2-decenal. The comparison of these LOD values and the concentrations calculated in the 15 samples (Table 5) revealed that many samples showed concentration values lower than the LODs in the case of ethyl propanoate, $(E)$-2-decenal and pentatonic acid. However, these problems did not fully explain the reproducibility RSD\% for these compounds, since their values (38.96, 36.65, 27.11\% respectively when QM1 is applied) were not the highest (Table 5).

\subsection{Limits of determination or quantification ( $L O Q)$}

The LOQ values calculated with the three methods are shown in Table 8 . The values were high (> $1.0 \mathrm{mg} / \mathrm{kg}$ in most of the cases) and did not correspond with the clearly distinguishable signals and high linearity observed in the chromatographic areas when the analyte was present at low concentrations $(<0.25 \mathrm{mg} / \mathrm{kg}$ ) (Table S3). In the case of method 1 , the LOQs were around $5 \mathrm{mg} / \mathrm{kg}$ for hexanal, 1-hexanol, 1-octen-3-ol, acetic acid and (E)-2-decenal. However, with calculation method 4, LOQs were in the range of $0.01-0.53 \mathrm{mg} / \mathrm{kg}$. Considering this method, the lowest LOQs $(<0.03 \mathrm{mg} / \mathrm{kg})$ corresponded to 1-hexanol, (Z)-3-hexenyl acetate, propanoic acid, octane, (E)-2hexenal, and 1-octen-3-ol. The highest LOQs (>0.07 mg/kg) corresponded to ethyl propanoate, hexanal, ethyl acetate, ethanol, nonanal, pentanoic acid and (E)-2-decenal. The concentrations calculated in the 15 samples were lower or close to the LOQ in most samples for ethyl propanoate, 1-octen-3-ol, (E)-2-decenal and pentanoic acid. However, as stated above, this did not seem to affect the RSD\% values for reproducibility (Table 5). On the contrary, the highest RSD\% value $(63.46 \%$ when QM1 was applied) was found for (E,E)-2,4-hexadienal (Table 5), which could be explained by the fact that its concentrations was close to the LOQ limit, even if all the concentrations were higher than the LOD. This could lead to some difficulties in integration and result in higher errors. 


\subsection{Comparative study of validations using SPME-GC-FID and SPME-GC-MS methods}

A comparative study of the SPME-GC-FID method carried out by three labs (Casadei et al., 2021) and the present SPME-GC-MS (applied by five labs) was made considering the values of the parameters studied in each validation for the set of 18 VOCs. Both studies were carried out on the same samples and with exactly the same procedure.

In terms of linearity, the mean values of $\mathrm{R}^{2}$ were slightly higher for MS (0.983) than for FID (0.977). In addition, higher $\mathrm{R}^{2}$ values were observed using QM1 with respect to QM2, both in FID and MS, which indicates a general improvement of the calibration results when the IS is added and used in quantification of the concentration of compounds. The VOCs that showed the highest linearity in their calibrations were ethyl propanoate and 3-methyl-1-butanol for FID $\left(\mathrm{R}^{2}=0.998\right)$ and octane, hexanal and 3-methyl-1-butanol for MS $\left(\mathrm{R}^{2}=0.996\right)$. The lowest linearity was observed for $(E)-2$ heptenal in FID $\left(\mathrm{R}^{2}=0.936\right)$ and for $(E)$-2-decenal in MS $\left(\mathrm{R}^{2}=0.942\right)$. In general terms, compounds presenting high $\mathrm{R}^{2}$ values for the labs that used FID matched with those that presented high linearity for the labs using MS. The same was observed for compounds with less linearity.

Regarding repeatability, MS presented lower mean RSD\% values in each of the three QMs applied (7.60\% for QM1, 6.00\% for QM2 and 5.70\% for QM3 in MS; compared to $11.52 \%, 8.18 \%$ and $9.65 \%$ in FID, respectively). Therefore, QM1 gave the highest mean RSD\% value, both in FID and MS, and the best repeatability was obtained by applying QM2 in FID and QM3 in MS. The RSD\% values considering the three QMs ranged between 3.60\% and 15.62\% for FID and between $2.21 \%$ and $17.23 \%$ for MS. Thus, the performance of the methods in terms of repeatability was similar when using the two detectors. The VOCs that showed the best repeatability (lower mean RSD\% value considering the three QMs) were acetic acid and propanoic acid with FID $(5.18 \%$ and 5.74\%, respectively) and (Z)-3-hexenyl acetate and (E)-2-hexenal with MS (3.76\% and 3.83\%, respectively). Ethyl propanoate and 1-octen-3-ol had the highest mean values of RSD\% in FID (13.80\% and 
$13.29 \%$, respectively), whereas ethyl propanoate, again, and hexanal $(11.37 \%$ and $10.14 \%$, respectively) had the worst repeatability in MS validation.

Considering the reproducibility of the method, both for FID and MS showed similar or better RSD\% values with QM1 compared with QM2 and QM3. However, the advantage of using QM1 is more evident in the method using MS. Thus, the mean RSD\% values of the 18 VOCs for QM1, QM2 and QM3 were $38.79 \%, 39.18 \%$ and $37.66 \%$ for FID and $31.77 \%, 48.02 \%$ and $55.41 \%$ for MS, respectively. On the other hand, of the 18 selected compounds, the use of IS in the quantification showed to have a positive effect in reproducibility (lower RSD\% for QM1 compared to QM2) in 7 compounds in FID and 16 compounds in MS. Considering only QM1, the mean RSD\% for the 18 VOCs quantified was lower in MS than in FID, ranging between $12.05 \%$ (octane) and $121.99 \%$ (ethyl propanoate) for FID; and between $13.26 \%$ (1-hexanol) and 63.46\% ((E,E)-2,4-hexadienal) for MS. However, excluding this anomalous value of RSD\% in ethyl propanoate in the validation with FID, the mean RSD\% for the rest of VOCs would be $32.59 \%$ and the maximum value of RSD\% would be 48.06\% for 1-hexanol. For 6 compounds (octane, ethyl acetate, 3-methyl-1-butanol, nonanal, (E,E)2,4-hexadienal, and propanoic acid), the RSD\% value was lower in the method using FID compared to MS, although 3 compounds (octane, ethyl acetate, $(E, E)-2,4$-hexadienal) had a clear difference, with the RSD\% for FID being approximately one half. For the rest of compounds (12), the RSD\% were lower for MS, and in 3 (ethyl propanoate, 1-hexanol, acetic acid) the RSD\% was the half as low or even less compared to the method using FID.

When comparing the recovery between the two methods, mean values closer to $100 \%$ were observed in the laboratories that used MS for QM1 and QM2 (94\% and 105\% with MS vs. 89\% and $115 \%$ with FID, respectively). QM3 had very high recovery values in both validations (mean values of $181 \%$ and $179 \%$ for FID and MS, respectively). Even though, as stated, the quantification with QM1 provided very similar average recovery results compared to QM2 in both validations, the mean deviation from 100\% was substantially lower for QM1 in the laboratories using MS (7.70\% applying 
QM1 vs. 16.40\% with QM2). The compound with the best recovery using QM1 was 6-methyl-5hepten-2-one in FID (99\%), and 3-methyl-1-butanol and 1-hexanol (100\%) in MS. The compound with deviation greater from 100\% was (E)-2-decenal, in both FID (160\%) and MS (72\%).

Precision, expressed as the RSD\% of the chromatographic areas corresponding to the IS (4methyl-2-pentanol) ranged from $4.52 \%$ to $9.65 \%$ (mean $7.56 \%$ ) in the validation with FID. Using MS, the RSD\% ranged from $4.02 \%$ to $15.44 \%$ for the five labs, with a mean RSD\% of $9.66 \%$. As observed, the obtained values were low, which suggested good precision for both FID and MS validations.

The LOD values of the 18 VOCs was calculated using 4 different methods. In both the validations with FID and MS, calculation method 4 had lower and more representative values for this parameter with respect to the other methods, and thus was the method of choice. In both cases, the values coincided with the visual analysis of peaks for most of the VOCs in the calibration chromatograms. On the other hand, the laboratories that used MS obtained mean values of LOD that were lower than the laboratories using FID $(0.03 \mathrm{mg} / \mathrm{kg}$ and $0.08 \mathrm{mg} / \mathrm{kg}$ with calculation method 4 , respectively). The compound with the lowest LOD in both validations was 1 -hexanol $(<0.005 \mathrm{mg} / \mathrm{kg}$ in FID and $0.01 \mathrm{mg} / \mathrm{kg}$ in MS), while the one with the highest value for this parameter was $(E)$-2decenal $(0.64 \mathrm{mg} / \mathrm{kg}$ in FID and $0.18 \mathrm{mg} / \mathrm{kg}$ in MS), for both types of detectors.

For the LOQ, the same conclusions as for the LOD were reached since the difference between the two limits is only a factor of 3 . In fact, the LOQ values were about 3 times greater than those obtained in the calculation of the LOD, ranging between $0.01 \mathrm{mg} / \mathrm{kg}$ (1-hexanol) and $1.93 \mathrm{mg} / \mathrm{kg}$ ((E)-2-decenal) in the validation with FID and between $0.01 \mathrm{mg} / \mathrm{kg}$ and $0.53 \mathrm{mg} / \mathrm{kg}$ (for the same two VOCs) in validation with MS. 


\section{Conclusions}

The purpose of this investigation was the peer validation study of a SPME-GC-MS method for analysis of selected VOCs to support sensory analysis in quality control of VOOs. This represents a further step forwards in the quali-quantitative evaluation of diagnostic volatile markers under the same analytical conditions of a method using FID as a detector (Casadei et al., 2021). This work was useful to make the entire process of full validation more robust and effective also thanks to the organization, within the OLEUM project, of a hands-on training workshop that focused on this method, and pre-trials as collaborative inter-laboratory experiments. After that, the proficiency of the method was also evaluated through a proper inter-laboratory trial with the active involvement of several external laboratories with a consolidated expertise in the olive oil analytical sector.

From this peer inter-laboratory study, method performance parameters obtained in each laboratory were investigated, compared and discussed with the aim to highlight similarities and eventual differences, as well as to calculate mean values and dispersion of the results. The quantification of the selected VOCs was carried out on the same samples by applying three different quantification methods (QMs): from analysis of all the dataset it turned out that the most promising method was QM1 using a calibration based on the IS and the external calibration curve $\left(\mathrm{A}_{\text {Analyte}} / \mathrm{A}_{\text {IS }}\right.$ vs. C $_{\text {Analyte }}$ ). Although QM1 showed slightly worse repeatability than the other methods, it had better accuracy and reproducibility. This finding was also observed for the FID method, even if with MS it was more evident. In general, satisfactory results were obtained for linearity, recovery, precision and repeatability parameters, although reproducibility has a rather high RSD\% (>40\%) for some compounds (ethyl propanoate, 6-methyl-hepten-2-one, and (E,E)-2,4-hexadienal).

This study compared the performance characteristics of the method when applied with FID or MS. Given that these two options provide advantages and disadvantages, and that they are alternatively available in the labs working in olive oil analysis, knowledge on their performance is needed. Only at the end of a full validation process with the involvement of a large number of 
laboratories participating on a voluntary basis, it will be possible to conduct a study aimed at individuating the concentration ranges of variability, as well as a proposal of limits, for the selected volatile compounds (especially those related to sensory defects) in relation to the different quality grades of VOOs. Moreover, also considering the pros that - for the samples analyzed herein - the sensory evaluation was performed by 6 different panels, the concentrations obtained could be related with the presence of sensory defects or positive attributes (fruity), thus being useful to define the ranges/limits for the selected markers in order to support the panel test.

Funding: This work was supported by the Horizon 2020 European Research project OLEUM "Advanced solutions for assuring the authenticity and quality of olive oil at a global scale", which has received funding from the European Commission within the Horizon 2020 Programme (20142020), grant agreement no. 635690. The information expressed in this article reflects the authors' views; the European Commission is not liable for the information contained herein.

\section{CRediT authorship contribution statement}

Ramón Aparicio-Ruiz: Conceptualization, Methodology, Formal analysis, Software, Data curation, Writing - original draft, Writing - review \& editing. Clemente Ortiz-Romero: Formal analysis, Methodology, Validation, Writing - review \& editing, Software, Data curation. Enrico Casadei: Conceptualization, Methodology, Validation, Formal analysis, Writing - original draft, Writing review \& editing. Diego L. García González: Conceptualization, Methodology, Validation, Data curation, Writing - original draft, Writing - review \& editing, Supervision. Maurizio Servili: Conceptualization, Methodology, Validation, Data curation, Writing - review \& editing, Supervision.

Roberto Selvaggini: Conceptualization, Methodology, Formal analysis, Data curation, Writing review \& editing. Florence Lacoste: Conceptualization, Methodology, Validation, Data curation, 
603 Writing - review \& editing, Supervision. Julien Escobessa: Methodology, Formal analysis, Data 604 curation, Writing - review \& editing. Stefania Vichi: Formal analysis, Methodology, Validation, 605 Data curation, Writing - review \& editing. Beatriz Quintanilla-Casas: Formal analysis, 606 Methodology, Data curation, Writing - review \& editing. Pierre Alain Golay: Conceptualization, 607 Methodology, Formal analysis, Data curation, Writing - review \& editing. Paolo Lucci: 608 Conceptualization, Methodology, Validation, Data curation, Writing - review \& editing, Supervision. 609 Erica Moret: Conceptualization, Methodology, Formal analysis, Data curation, Writing - review \& 610 editing. Enrico Valli: Conceptualization, Methodology, Validation, Data curation, Writing - original 611 draft, Writing - review \& editing, Supervision. Alessandra Bendini: Conceptualization, 612 Methodology, Validation, Data curation, Writing - review \& editing, Supervision. Tullia Gallina 613 Toschi: Conceptualization, Methodology, Validation, Project administration, Writing - review \& 614 editing, Supervision.

616 Acknowledgements: The authors are grateful to the sensory panel leaders and tasters involved in the 617 OLEUM project (Eurofins, Germany; ITERG, France; IPTPO, Croatia; UNIBO, Italia; UZZK, 618 Turkey; ZRS/UP, Slovenia) and to the numerous companies that provided the commercial virgin olive 619 oils for this investigation. The authors would like to express their gratitude to Prof. Lanfranco Conte 620 for his contribution in terms of discussion and ideas on the herein presented method. 
622

623

624

625

626

627

628

629

630

631

632

633

634

635

636

637

638

Aparicio, R., Morales, M. T., \& García-González, D. L. (2012). Towards new analyses of aroma and volatiles to understand sensory perception of olive oil. European Journal of Lipid Science and Technology, 114, 1114-1125. https://doi.org/10.1002/ejlt.201200193.

Aparicio-Ruiz, R., García-González, D. L., Morales, M. T., Lobo-Prieto, A., \& Romero, I. (2018). Comparison of two analytical methods validated for the determination of volatile compounds in virgin olive oil: GC-FID vs GC-MS. Talanta, 187, 133-141. https://doi.org/10.1016/j.talanta.2018.05.008

Aparicio-Ruiz, R., Morales, M. T., \& Aparicio, R. (2019). Does authenticity of virgin olive oil sensory quality require input from chemistry? European Journal of Lipid Science and Technology, 121, 1900202. https://doi.org/10.1002/ejlt.201900202.

Aparicio-Ruiz, R., Ortiz Romero, C., Casadei, E., García González D. L., Servili M., Selvaggini R., et al. (2021). OLEUM Project. Data of a harmonized SPME-GC-MS method for the analysis of selected volatile compounds in virgin olive oils [Dataset]. CSIC, http://dx.doi.org/10.20350/digitalCSIC/13965.

Barbieri, S., Bubola, K. B., Bendini, A., Bučar-Miklavčič, M., Lacoste, F., Tibet, U., et al. (2020a). Alignment and proficiency of virgin olive oil sensory panels: The OLEUM approach. Foods, 9, 355. https://doi.org/10.3390/foods9030355.

Barbieri, S., Cevoli, C., Bendini, A., Quintanilla-Casas, B., García-González, D. L., \& Gallina Toschi, T. (2020b). Flash gas chromatography in tandem with chemometrics: a rapid screening tool for quality grades of virgin olive oils. Foods, 9, 862. https://doi.org/10.3390/foods9070862.

Desimoni, E., \& Brunetti, B. (2015). About estimating the limit of detection by the signal to noise approach. Pharmaceutica Analytica Acta, 6, 1000355. https://doi.org/10.4172/2153-2435.1000355. 
643 Casadei, E., Valli, E., Aparicio-Ruiz, R., Ortiz Romero, C., García González, D. L., Vichi, S., et al. 644 (2021). Peer inter-laboratory validation study of a harmonized SPME-GC-FID method for the 645 analysis of selected volatile compounds in virgin olive oils. Food Control, 123, 107823. 646 https://doi.org/10.1016/j.foodcont.2020.107823.

647 Cecchi, L., Migliorini, M., \& Mulinacci, N. (2021). Virgin olive oil volatile compounds: 648 Composition, sensory characteristics, analytical approaches, quality control, and authentication. 649 Journal of Agricultural and Food Chemistry, 69, 2013-2040. 650 https://doi.org/10.1021/acs.jafc.0c07744.

651 Cecchi, L., Migliorini, M., Giambanelli, E., Rossetti, A., Cane, A., Melani, F., et al. (2019). 652 Headspace solid-phase microextraction-gas chromatography-mass spectrometry quantification of 653 the volatile profile of more than 1200 virgin olive oils for supporting the panel test in their 654 classification: comparison of different chemometric approaches. Journal of Agricultural and Food 655 Chemistry, 67, 9112-9120. https://doi.org/10.1021/acs.jafc.9b03346.

656 Conte, L., Bendini, A., Valli, E., Lucci, P., Moret, S., Maquet A., et al. (2020). Olive oil quality and 657 authenticity: A review of current EU legislation, standards, relevant methods of analyses, their 658 drawbacks and recommendations for the future. Trends in Food Science \& Technology, 105, 659 485-493. https://doi.org/10.1016/j.tifs.2019.02.025.

660 European Commission Regulation (1991). On the characteristics of olive oil and olive residue oil and 661 on the relevant methods of analysis, and subsequent amendments. Official Journal of European 662 Community 11 (L248), 1-102, 2568/91.

663 Gallina Toschi, T., Valli, E., Conte, L., García-González, D. L., Maquet, A., Brereton, P., et al. 664 (2017). EU project OLEUM: Better solutions to protect olive oil quality and authenticity. Agro Food 665 Ind. Hi-Tech, 28, 2-3. https://www.teknoscienze.com/tks_article/eu-project-oleum-better-solutions666 to-protect-olive-oil-quality-and-authenticity/ 
667 García González D.L., Aparicio, R., \& Aparicio-Ruiz, R (2018). Olive oil. In: J.F. Morin \& Michèle 668 Lees (Eds.), FoodIntegrity Handbook: A guide to food authenticity issues and analytical solutions 669 (pp. 335-358). Eurofins Analytics France. https://doi.org/10.32741/fihb.18.oliveoil.

670 García-González, D. L., Aparicio, R. (2004). Classification of different quality virgin olive oils by 671 metal-oxide sensors. European Food Research Technology., 218, 484-487. 672 https://doi.org/10.1007/s00217-003-0855-4.

673 García-González, D. L., Aparicio, R. (2010). Research in olive oil: Challenges for the near future. 674 Journal of Agricultural and Food Chemistry, 58, 12569-12577. https://doi.org/10.1021/jf102735n

675 García-González, D. L., Tena, N., \& Aparicio, R. (2007). Characterization of olive paste volatiles to 676 predict the sensory quality of virgin olive oil. European Journal of Lipid Science and Technology, 677 109, 663-672. https://doi.org/10.1002/ejlt.200700056.

678 García-González, D. L., Vivancos, J., \& Aparicio, R. (2011). Mapping brain activity induced by 679 olfaction of virgin olive oil aroma. Journal of Agricultural and Food Chemistry, 59, 10200-10210. 680 https://doi.org/10.1021/jf202106b.

681 Giuffrida, F., Golay, P-A., Destaillats, F., Hug, B., \& Dionisi, F. (2005). Accurate determination of 682 hexanal in beef bouillons by headspace solid-phase microextraction gas-chromatography mass683 spectrometry. European Journal of Lipid Science and Technology, 107, 792-798. 684 https://doi.org/10.1002/ejlt.200500240.

685 International Olive Council (IOC). (1987). Sensory analysis of olive oil method for the organoleptic 686 assessment of virgin olive oil. IOOC/T.20/Doc. no. 3.

687 International Olive Council (IOC). (2020). Guidelines for the management of virgin olive oil tasting 688 panels in the event of a pandemic. COI/MPP/Doc. No 1/Rev 1 November 2020.

689 International Organization for Standardization (ISO). (2016). Chemistry - layouts for standards - Part 690 2. Methods of chemical analysis, 78-2, 1999. 
691 International Organization for Standardization (ISO). (2019). Accuracy (trueness and precision) of 692 measurement methods and results - Part 2. Basic method for the determination of repeatability and 693 reproducibility of a standard measurement method, 5725-2, 2019.

694 Jimenez-Alvarez D., Giuffrida F., Golay P-A, Cotting C., Destaillats F., Dionisi F., et al. (2008b). 695 Profiles of volatile compounds in milk containing fish oil analyzed by HS-SPME-GC/MS, European 696 Journal of Lipid Science and Technology, 110, 277-283. https://doi.org/10.1002/ejlt.200700148.

697 Jimenez-Alvarez, D., Giuffrida, F., Golay, P-A., Cotting, C., Lardeau, A., \& Keely, B.J. (2008a). 698 Antioxidant activity of oregano, parsley, and olive mill wastewaters in bulk oils and oil-in-water 699 emulsions enriched in fish oil. Journal of Agricultural and Food Chemistry, 56, 7151-7159. 700 https://doi.org/10.1021/jf801154r.

701 Kalua, C. M., Allen, M. S., Bedgood, D. R., Bishop, A. G., Prenzler, P. D., \& Robards, K. (2007). 702 Olive oil volatile compounds, flavour development and quality: A critical review. Food Chemistry, 703 100, 273-286. https://doi.org/10.1016/j.foodchem.2005.09.059.

704 Kalua, C. M., Bedgood, D. R., \& Prenzler, P. D. (2006). Development of a headspace solid phase 705 microextraction-gas chromatography method for monitoring volatile compounds in extended time 706 course experiments of olive oil. Analytica Chimica Acta, 556, 407-414. 707 https://doi.org/10.1016/j.aca.2005.09.050.

708 Kanavouras, A., \& Hernandez, R. J. (2006). The analysis of volatiles from thermally oxidized virgin 709 olive oil using dynamic sorption-thermal desorption and solid phase micro-extraction techniques. 710 International Journal of Food Science and Technology, 41, 743-750. https://doi.org/10.1111/j.1365$711 \quad 2621.2005 .01019 . x$

712 Kanavouras, A., Kiritsakis, A., \& Hernandez, R. J. (2005). Comparative study on volatile analysis of 713 extra virgin olive oil by dynamic headspace and solid phase micro-extraction. Food Chemistry, 90, 69-79. https://doi.org/10.1016/j.foodchem.2004.03.025. 
715 Morales, M. T., Aparicio-Ruiz, R., \& Aparicio, R. (2013). Chromatographic methodologies: 716 Compounds for olive oil odor issues. In R. Aparicio-Ruiz, J. Harwood (Eds.), Handbook of Olive Oil: 717 Analysis and Properties (pp. 261-309). Springer.

718 Morales, M. T., Luna, G., \& Aparicio, R. (2005). Comparative study of virgin olive oil sensory 719 defects. Food Chemistry, 91, 293-301. https://doi.org/10.1016/j.foodchem.2004.06.011.

720 Oliver-Pozo, C., Aparicio-Ruiz, R., Romero, I., \& García-González, D. L. (2015). Analysis of volatile markers for virgin olive oil aroma defects by SPME-GC/FID: Possible sources of incorrect data. Journal of Agricultural and Food Chemistry, 63, 10477-10483. 723 https://doi.org/10.1021/acs.jafc.5b03986.

724 Oliver-Pozo, C., Trypidis, D., Aparicio, R., García-González, D. L., Aparicio-Ruiz, R. (2019). 725 Implementing dynamic headspace with SPME sampling of virgin olive oil volatiles: Optimization, 726 quality analytical study, and performance testing. Journal of Agricultural and Food Chemistry, 67, 727 2086-2097. https://doi.org/10.1021/acs.jafc.9b00477.

728 Reboredo-Rodríguez, P., González-Barreiro, C., Cancho-Grande, B., \& Simal-Gándara, J. (2012). 729 Dynamic headspace/GC-MS to control the aroma fingerprint of extra-virgin olive oil from the same 730 and different olive varieties. Food Control, 25, 684-695. 731 https://doi.org/10.1016/j.foodcont.2011.12.005.

732 Romero, I., García-González, D. L., Aparicio-Ruiz, R., \& Morales, M. T. (2015). Validation of 733 SPME-GCMS method for the analysis of virgin olive oil volatiles responsible for sensory defects. 734 Talanta, 134, 394-401. https://doi.org/10.1016/j.talanta.2014.11.032.

735 Romero, I., García-González, D. L., Aparicio-Ruiz, R., \& Morales, M. T. (2017). Study of volatile 736 compounds of virgin olive oils with 'frostbitten olives' sensory defect. Journal of Agricultural and Food Chemistry, 65, 4314-4320. https://doi.org/10.1021/acs.jafc.7b00712. 
738 Salas, J. J., Sánchez, C., García-González, D. L., \& Aparicio, R. (2005). Impact of the suppression 739 of lipoxygenase and hydroperoxide lyase on the quality of the green odor in green leaves. Journal 740 of Agricultural and Food Chemistry, 53, 1648-1655. https://doi.org/10.1021/jf0403311.

741 Serrano, A., de la Rosa, R., Sánchez-Ortiz, A., \& León, L. (2020) Genetic and environmental effect 742 on volatile composition of extra virgin olive oil. European Journal of Lipid Science and Technology, 743 122, 1-10. https://doi.org/10.1002/ejlt.202000162.

744 Servili, M., Esposto, S., Taticchi, A., Urbani, S., Di Maio, I., Veneziani, G., \& Selvaggini, R. (2015). 745 New approaches to virgin olive oil quality, technology, and by-products valorization. European 746 Journal of Lipid Science and Technology, 117, 1882-1892. https://doi.org/10.1002/ejlt.201500138.

747 Shrivastav, A., \& Gupta, V. P. (2011). Methods for the determination of limit of detection and limit 748 of quantification of the analytical methods. Chronicles of Young Scientists, 2, 21-25. 749 https://doi.org/10.4103/2229-5186.79345.

750 Van den Dool, H., \& Kratz, P. D. (1963). A generalization of the retention index system including 751 linear temperature programmed gas-liquid partition chromatography. Journal of Chromatography A, 752 11, 463-471. https://doi.org/10.1016/S0021-9673(01)80947-X.

753 Vichi, S., Castellote, A. I., Pizzale, L., Conte, L. S., Buxaderas, S., \& López-Tamames, E. (2003). 754 Analysis of virgin olive oil volatile compounds by headspace solid-phase microextraction coupled 755 to gas chromatography with mass spectrometric and flame ionization detection. Journal of 756 Chromatography A, 983 (1-2), 19-33. https://doi.org/10.1016/S0021-9673(02)01691-6. 


\section{$758 \quad$ Figure captions}

759 Figure 1. Chromatogram of volatile compounds of a lampante olive oil and a virgin olive analysed 760 by SPME-GC-MS. The correspondence of the codes with the volatile compounds is shown in Table 7611.

762 Figure 2. Calibration curves of ethyl propanoate built for the quantification method 2 (QM2). 
Table 1. Selected volatile compounds, CAS numbers, purities of chemical standards, linear retention times (LRT), characteristic m/z in the mass spectra and sensory defects or positive attribute to which they are related.

\begin{tabular}{|c|c|c|c|c|c|c|c|}
\hline Code & Volatile compound & CAS number & $\begin{array}{l}\text { Purity of the chemical } \\
\text { standard }(\%)^{\mathrm{a}}\end{array}$ & $\mathbf{L R I}^{\mathbf{b}}$ & $\mathbf{S M}_{\mathbf{x}} \mathbf{c}$ & Characteristic m/z & Related defect/attribute $^{d}$ \\
\hline 1 & Octane & $111-65-9$ & 99.7 & $802 \pm 1.85$ & A & 85 & Fusty/muddy sediment \\
\hline 2 & Ethyl acetate & $141-78-6$ & 99.8 & $899 \pm 0.84$ & A & 43 & Winey-vinegary \\
\hline 3 & Ethanol & $64-17-5$ & 99.9 & $933 \pm 1.06$ & B & 31,45 & Winey-vinegary, fusty/muddy sediment \\
\hline 4 & Ethyl propanoate & $105-37-3$ & 99.7 & $954 \pm 7.23$ & A & 57 & Frostbitten olives \\
\hline 5 & Hexanal & $66-25-1$ & 98 & $1080 \pm 8.02$ & $\mathrm{~B}$ & 44 & Rancid \\
\hline 6 & 3-Methyl-1-butanol & $123-51-3$ & 98.5 & $1210 \pm 4.53$ & A & 55,70 & Fusty/muddy sediment \\
\hline 7 & (E)-2-Hexenal & $6728-26-3$ & 97.0 & $1215 \pm 9.18$ & $\mathrm{~B}$ & 69,83 & Fruity \\
\hline 8 & (Z)-3-Hexenyl acetate & $3681-71-8$ & 98.0 & $1312 \pm 4.96$ & B & 67,82 & Fruity \\
\hline 9 & (E)-2-Heptenal & $18829-55-5$ & 95 & $1321 \pm 10.08$ & A & 83 & Musty-humid-earthy, rancid \\
\hline 10 & 6-Methyl-5-hepten-2-one & $110-93-0$ & 97.0 & $1337 \pm 10.00$ & A & 108 & Fusty/muddy sediment \\
\hline 11 & 1-Hexanol & $111-27-3$ & 99.9 & $1356 \pm 4.79$ & $\mathrm{~B}$ & 56 & Fruity \\
\hline 12 & Nonanal & $124-19-6$ & 95 & $1392 \pm 9.21$ & $\mathrm{~B}$ & 98 & Rancid \\
\hline 13 & 1-Octen-3-ol & $142-83-6$ & 98.0 & $1453 \pm 6.70^{\mathrm{e}}$ & $\mathrm{B}$ & 81 & Musty-humid-earthy \\
\hline 14 & $(E, E)-2,4-H e x a d i e n a l$ & $3391-86-4$ & 95.0 & $1401 \pm 10.71^{\mathrm{e}}$ & A & 57 & Rancid \\
\hline 15 & Acetic acid & $64-19-7$ & 99.8 & $1475 \pm 35.27$ & $\mathrm{~B}$ & 60 & Winey-vinegary \\
\hline 16 & Propanoic acid & $79-09-4$ & 99.8 & $1547 \pm 46.54$ & A & 74 & $\begin{array}{c}\text { Fusty/muddy sediment, musty-humid- } \\
\text { earthy }\end{array}$ \\
\hline 17 & (E)-2-Decenal & $3913-81-3$ & 95.0 & $1644 \pm 10.39$ & A & 70 & Rancid \\
\hline 18 & Pentanoic acid & $109-52-4$ & 99.8 & $1759 \pm 32.92$ & A & 60,73 & Rancid \\
\hline
\end{tabular}

${ }^{a}$ Minimum purity as expressed by the supplier.

${ }^{\mathrm{b}}$ LRI: Linear Retention Index, Relative Retention Time indicative parameter. Mean \pm error from two labs that reported the results (UNIUD and UNIPG).

${ }^{c}$ SM: Standard mixture containing each volatile compound (SM-A: low concentration range $0.05-10.00 \mathrm{mg} / \mathrm{kg}$; SM-B: high concentration range 0.20-25.00 mg/kg).

${ }^{\mathrm{d}}$ Main perceived defect/attribute when the volatile compound is at high concentrations (above its odor threshold). Some compounds may be related to more than one defect/attribute.

e The order of these two compounds may be altered depending on the column brand and/or column film thickness. 
Table 2. Characteristics of the GC-MS instruments used in each lab during the peer inter-laboratory validation study.

\begin{tabular}{|c|c|c|c|c|c|}
\hline & Laboratory 1 & Laboratory 2 & Laboratory 3 & Laboratory 4 & Laboratory 5 \\
\hline $\begin{array}{c}\text { GC } \\
\text { Instrument } \\
\text { (Equipment) }\end{array}$ & $\begin{array}{l}\text { 7890B, Agilent } \\
\text { Technologies }^{1}\end{array}$ & $\begin{array}{c}\text { 78900A, } \\
\text { Agilent } \\
\text { Technologies }\end{array}$ & $\begin{array}{l}\text { 7890B, Agilent } \\
\text { Technologies } 1 \text {, } \\
\text { equipped with a } \\
\text { "Multimode } \\
\text { Injector" (MMI) } \\
\text { 7693A } \\
\end{array}$ & $\begin{array}{l}\text { 6890N, Agilent } \\
\text { Technologies }^{1}\end{array}$ & $\begin{array}{l}\text { HP6890, Agilent } \\
\text { Technologies }^{1}\end{array}$ \\
\hline Autosampler & $\begin{array}{c}\text { PAL RSI 85, } \\
\text { CTC Analytics } \\
\text { AG }^{2}\end{array}$ & $\begin{array}{c}\text { Combipal, CTC } \\
\text { Analytics }^{2}\end{array}$ & $\begin{array}{c}\text { PAL3 RSI 120, } \\
\text { CTC Analytics } \\
\mathrm{AG}^{2}\end{array}$ & $\begin{array}{l}\text { Combi-PAL, CTC } \\
\text { Analytics } \mathrm{AG}^{2}\end{array}$ & $\begin{array}{c}\text { MPS } \\
\text { (MultiPurpose } \\
\text { Sampler), } \\
\text { GERSTEL GmbH } \\
\text { \& Co.KG }{ }^{3} \\
\end{array}$ \\
\hline GC column & $\begin{array}{c}\text { DB-WAX, } \\
\text { Agilent J\&W }{ }^{1} \text {, } \\
\text { CA. } 60 \mathrm{~m} \text {; I.D. } \\
0.25 \mathrm{~mm} \text {; film } \\
\text { thickness } 0.25 \\
\mu \mathrm{m}\end{array}$ & $\begin{array}{c}\text { ZB-WAX } \\
\text { Zebron, } \\
\text { Phenomenex }{ }^{4}, \\
60 \mathrm{~m} \text { x } 250 \mu \mathrm{m} \\
\text { x } 0.25 \mu \mathrm{m},\end{array}$ & $\begin{array}{c}\text { HP-INNOWax, } \\
\text { Agilent } \\
\text { Technologies }{ }^{1}, 60 \\
\text { m; i.d. } 0.25 \mathrm{~mm} ; \\
\text { film thickness } 0.25 \\
\mu \mathrm{m} \\
\end{array}$ & $\begin{array}{l}\text { Supelcowax-10, } \\
\text { Supelco } 5,60 \mathrm{~m} \text {; } \\
\text { I.D. } 0.25 \mathrm{~mm} \text {; } \\
\text { film thickness } \\
\quad 0.25 \mu \mathrm{m} \text {. }\end{array}$ & $\begin{array}{c}\text { DB-WAX Ultra } \\
\text { Inert, Agilent } \\
\mathrm{J}^{1} \mathrm{~W}^{1} \text {, length } 60 \\
\mathrm{~m}, \text { i.d. } 0.25 \mathrm{~mm} ; \\
\text { film thickness } 0.5 \\
\mu \mathrm{m}\end{array}$ \\
\hline $\begin{array}{c}\text { MS } \\
\text { instrument } \\
\text { (equipment) }\end{array}$ & $\begin{array}{c}\text { 5977A, } \\
\text { Agilent } \\
\text { Technologies }^{1}, \\
\text { single } \\
\text { quadrupole } \\
\text { mass } \\
\text { spectrometer, } \\
\end{array}$ & $\begin{array}{c}\text { 5975C, Agilent } \\
\text { Technologies }{ }^{1}, \\
\text { single } \\
\text { quadrupole } \\
\text { mass } \\
\text { spectrometer, }\end{array}$ & $\begin{array}{l}\text { 5977B, Agilent } \\
\text { Technologies }{ }^{1}, \\
\text { single quadrupole } \\
\text { mass spectrometer } \\
\text { with EI Extractor } \\
\text { (XTR) source }\end{array}$ & $\begin{array}{l}\text { 5975C, Agilent } \\
\text { Technologies }{ }^{1} \text {, } \\
\text { inert XL } \\
\text { quadrupolar } \\
\text { analyser }\end{array}$ & $\begin{array}{l}\text { MSD5975, Agilent } \\
\text { Technologies }{ }^{1}, \\
\text { single quadrupole } \\
\text { mass spectrometer }\end{array}$ \\
\hline MS database & NIST v14 ${ }^{6}$ & $\begin{array}{c}\text { NIST MS } \\
\text { Search } 2.0^{6}\end{array}$ & NIST v1 $14^{6}$ & Wiley $6^{7}$ & NIST v14 ${ }^{6}$ \\
\hline $\begin{array}{c}\text { GC-MS } \\
\text { Interface } \\
\text { Temp. } \\
\end{array}$ & $280^{\circ} \mathrm{C}$ & $275^{\circ} \mathrm{C}$ & $260^{\circ} \mathrm{C}$ & $280^{\circ} \mathrm{C}$ & $220^{\circ} \mathrm{C}$ \\
\hline $\begin{array}{c}\text { Ion source } \\
\text { temperature }\end{array}$ & $175^{\circ} \mathrm{C}$ & $230^{\circ} \mathrm{C}$ & $200^{\circ} \mathrm{C}$ & $230^{\circ} \mathrm{C}$ & $200^{\circ} \mathrm{C}$ \\
\hline $\begin{array}{c}\text { Mass range } \\
\mathbf{m} / \mathbf{z}\end{array}$ & $31-350 \mathrm{~m} / \mathrm{z}$ & $30-300 \mathrm{~m} / \mathrm{z}$ & $25-350 \mathrm{~m} / \mathrm{z}$ & $35-300 \mathrm{~m} / \mathrm{z}$ & $29-350 \mathrm{~m} / \mathrm{z}$ \\
\hline $\begin{array}{l}\text { Quadrupole } \\
\text { temperature }\end{array}$ & $150^{\circ} \mathrm{C}$ & $150^{\circ} \mathrm{C}$ & $190^{\circ} \mathrm{C}$ & $150^{\circ} \mathrm{C}$ & $150^{\circ} \mathrm{C}$ \\
\hline Scan rate & 1.6 scans $/ \mathrm{s}$ & $5.1 \mathrm{scan} / \mathrm{s}$ & $4.3 \mathrm{scan} / \mathrm{s}$ & 5.1 scans $/ \mathrm{s}$ & 2.0 scans $/ \mathrm{s}$ \\
\hline
\end{tabular}

Note: ${ }^{1}$, Agilent Technologies, Santa Clara, CA, USA ; ${ }^{2}$, CTC Analytics AG, Zwingen, Switzerland; ${ }^{3}$, GERSTEL GmbH \& Co.KG, Mülheim an der Ruhr, Germany; ${ }^{4}$, Torrance, CA, USA; ${ }^{5}$, Bellefonte, PA, USA; ${ }^{6}$, Gaithersburg, MD; ${ }^{7}$, Hoboken, NJ, USA. 
Table 3. Linearity expressed as $\mathrm{R}^{2}$ (mean and standard deviation) computed from the calibration curves used in the quantification methods 1 and 2 (QM1, QM2) for the 18 volatile compounds.

\begin{tabular}{lcc}
\hline \multicolumn{1}{c}{ Volatile compounds } & QM1 & QM2 \\
\hline Octane & $0.996 \pm 0.003$ & $0.966 \pm 0.038^{\mathrm{a}}$ \\
Ethyl acetate & $0.982 \pm 0.023^{\mathrm{a}}$ & $0.906 \pm 0.078^{\mathrm{a}}$ \\
Ethanol & $0.984 \pm 0.011^{\mathrm{a}}$ & $0.953 \pm 0.047^{\mathrm{a}}$ \\
Ethyl propanoate & $0.994 \pm 0.008$ & $0.939 \pm 0.053^{\mathrm{a}}$ \\
Hexanal & $0.996 \pm 0.003$ & $0.980 \pm 0.021$ \\
3-methyl-1-butanol & $0.996 \pm 0.002$ & $0.941 \pm 0.068^{\mathrm{c}}$ \\
(E)-2-Hexenal & $0.990 \pm 0.009^{\mathrm{b}}$ & $0.994 \pm 0.007^{\mathrm{b}}$ \\
(Z)-3-Hexenyl acetate & $0.987 \pm 0.012^{\mathrm{b}}$ & $0.992 \pm 0.006^{\mathrm{b}}$ \\
(E)-2-Heptenal & $0.976 \pm 0.027^{\mathrm{b}}$ & $0.997 \pm 0.001$ \\
6-Methyl-5-hepten-2-one & $0.975 \pm 0.025^{\mathrm{b}}$ & $0.997 \pm 0.001$ \\
1-Hexanol & $0.993 \pm 0.006$ & $0.992 \pm 0.005$ \\
Nonanal & $0.976 \pm 0.024$ & $0.990 \pm 0.007$ \\
1-Octen-3-ol & $0.983 \pm 0.019$ & $0.993 \pm 0.005$ \\
(E,E)-2,4-Hexadienal & $0.975 \pm 0.027^{\mathrm{d}}$ & $0.997 \pm 0.002$ \\
Acetic acid & $0.993 \pm 0.005$ & $0.989 \pm 0.011$ \\
Propanoic acid & $0.983 \pm 0.028^{\mathrm{b}}$ & $0.995 \pm 0.005$ \\
(E)-2-Decenal & $0.942 \pm 0.057^{\mathrm{b}}$ & $0.966 \pm 0.025^{\mathrm{b}}$ \\
Pentanoic acid & $0.969 \pm 0.032^{\mathrm{b}}$ & $0.993 \pm 0.008^{\mathrm{b}}$ \\
\hline aCerain sara &
\end{tabular}

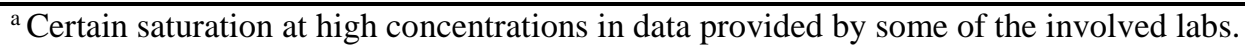

${ }^{\mathrm{b}}$ Certain lower sensitivity (lower slope) at low concentrations in data provided by some of the involved labs. 
Table 4. Repeatability expressed as mean RSD\%.

\begin{tabular}{lccc}
\hline \multicolumn{1}{c}{ Volatile compounds } & \multicolumn{3}{c}{ RSD\% $($ Mean \pm SD $)$} \\
\cline { 2 - 4 } & QM1 & QM2 & QM3 \\
\hline Octane & $6.77 \pm 4.33^{\mathrm{a}}$ & $7.95 \pm 4.11$ & $6.47 \pm 4.91$ \\
Ethyl acetate & $6.99 \pm 3.49$ & $4.77 \pm 0.21$ & $5.75 \pm 4.02$ \\
Ethanol & $9.51 \pm 2.72$ & $6.21 \pm 2.14$ & $6.52 \pm 1.94$ \\
Ethyl propanoate & $15.27 \pm 15.87^{\mathrm{a}}$ & $15.55 \pm 15.63$ & $15.13 \pm 17.34$ \\
Hexanal & $5.49 \pm 3.67$ & $4.84 \pm 2.00$ & $4.53 \pm 1.94$ \\
3-Methyl-1-butanol & $5.09 \pm 1.80$ & $5.63 \pm 2.58$ & $2.88 \pm 2.44$ \\
(E)-2-Hexenal & $4.15 \pm 1.74$ & $2.99 \pm 0.40$ & $2.21 \pm 1.30$ \\
(Z)-3-Hexenyl acetate & $5.23 \pm 0.55^{\mathrm{c}}$ & $4.86 \pm 0.84^{\mathrm{d}}$ & $3.11 \pm 0.61^{\mathrm{cd}}$ \\
(E)-2-Heptenal & $5.38 \pm 0.76$ & $4.75 \pm 4.23$ & $3.31 \pm 3.61$ \\
6-Methyl-5-hepten-2-one & $5.05 \pm 1.17$ & $5.82 \pm 0.89$ & $4.40 \pm 0.07$ \\
1-Hexanol & $3.89 \pm 1.46$ & $4.12 \pm 0.72^{\mathrm{d}}$ & $2.39 \pm 0.34^{\mathrm{d}}$ \\
Nonanal & $11.84 \pm 7.33^{\mathrm{a}}$ & $9.89 \pm 3.96$ & $7.36 \pm 9.39$ \\
1-Octen-3-ol & $6.98 \pm 1.59$ & $5.40 \pm 0.98$ & $5.84 \pm 3.03$ \\
(E,E)-2,4-Hexadienal & $8.51 \pm 2.99$ & $4.20 \pm 0.72$ & $6.79 \pm 5.13$ \\
Acetic acid & $7.87 \pm 0.47^{\mathrm{b}}$ & $3.48 \pm 2.59^{\mathrm{b}}$ & $5.48 \pm 3.09$ \\
Propanoic acid & $5.70 \pm 0.19^{\mathrm{b}}$ & $2.35 \pm 1.56^{\mathrm{b}}$ & $3.32 \pm 2.08$ \\
(E)-2-Decenal & $17.23 \pm 5.08^{\mathrm{c}}$ & $12.00 \pm 2.77$ & $13.86 \pm 5.10^{\mathrm{c}}$ \\
Pentanoic acid & $5.83 \pm 0.27^{\mathrm{b}}$ & $3.17 \pm 0.58^{\mathrm{b}}$ & $2.83 \pm 1.86$ \\
\hline OOne & & \\
\hline & & & \\
\hline
\end{tabular}

${ }^{\mathrm{a}}$ One outlier has been removed (Grubbs test $\mathrm{p}<0.05$ ).

${ }^{\mathrm{b}}$ Significant difference $(p<0.05)$ between QM1 and QM2.

${ }^{\mathrm{c}}$ Significant difference $(p<0.05)$ between QM1 and QM3.

${ }^{\mathrm{d}}$ Significant difference $(p<0.05)$ between QM2 and QM3. 
Table 5. Reproducibility values for the SPME-GC-MS method expressed as the mean of the RSD\%, calculated for each of the 15 analyzed samples (S1-S15). The concentration ranges (minimum and maximum values) and the mean RSD\% values are also shown.

\begin{tabular}{|c|c|c|c|c|c|c|c|c|c|c|c|c|c|c|c|c|c|c|}
\hline \multirow{2}{*}{ Compounds } & \multicolumn{15}{|c|}{ Concentration range (mg/kg) in samples (S) - Minimum (first row)/Maximum (second row) } & \multirow{2}{*}{ RSD\% QM1 ${ }^{\mathrm{a}}$} & \multirow{2}{*}{ RSD\% QM2a } & \multirow{2}{*}{ RSD\% QM3 } \\
\hline & S1 & S2 & S3 & S4 & S5 & S6 & S7 & S8 & S9 & S10 & S11 & S12 & S13 & S14 & S15 & & & \\
\hline \multirow{2}{*}{ Octane } & $0.02^{\mathrm{f}}$ & 0.06 & 0.06 & 0.08 & 1.18 & 0.06 & $0.02^{\mathrm{f}}$ & 0.53 & 0.03 & 0.12 & 0.07 & $<0.01^{\text {ef }}$ & 0.96 & $0.02^{\mathrm{f}}$ & 0.20 & \multirow{2}{*}{$38.50^{\mathrm{bc}}$} & \multirow{2}{*}{$68.01^{\text {bd }}$} & \multirow{2}{*}{$53.92^{\mathrm{cd}}$} \\
\hline & 0.07 & 0.23 & 0.17 & 0.18 & 3.08 & 0.15 & 0.06 & 1.17 & 0.06 & 0.24 & 0.12 & $0.02^{\mathrm{f}}$ & 1.37 & 0.06 & 0.54 & & & \\
\hline \multirow{2}{*}{ Ethyl acetate } & $0.02^{\mathrm{ef}}$ & 0.11 & $<0.01^{\mathrm{ef}}$ & 0.65 & 0.62 & 0.82 & 0.51 & 0.16 & 0.09 & 0.70 & 0.29 & $0.03^{\mathrm{f}}$ & 0.14 & 0.11 & 0.16 & \multirow{2}{*}{$28.17^{\mathrm{bc}}$} & \multirow{2}{*}{$71.28^{\mathrm{bd}}$} & \multirow{2}{*}{$51.93^{\mathrm{cd}}$} \\
\hline & $0.04^{\mathrm{f}}$ & 0.22 & $0.01^{\mathrm{f}}$ & 0.92 & 0.72 & 1.65 & 0.94 & 0.28 & 0.17 & 0.92 & 0.53 & $0.06^{\mathrm{f}}$ & 0.37 & 0.19 & 0.34 & & & \\
\hline \multirow{2}{*}{ Ethanol } & 0.14 & 0.37 & $0.07^{\mathrm{f}}$ & 4.64 & 18.16 & 5.60 & 9.52 & 3.09 & 1.72 & 4.41 & 16.67 & 1.21 & 12.01 & 4.03 & 1.67 & \multirow{2}{*}{$32.33^{\mathrm{c}}$} & \multirow{2}{*}{$40.07^{\mathrm{d}}$} & \multirow{2}{*}{$52.52^{\mathrm{cd}}$} \\
\hline & 0.40 & 1.17 & 0.31 & 12.92 & 24.60 & 11.46 & 14.13 & 5.27 & 3.64 & 11.43 & 25.26 & 2.55 & 18.52 & 6.43 & 4.94 & & & \\
\hline \multirow[b]{2}{*}{ Ethyl propanoate } & $<0.01^{\mathrm{ef}}$ & $<0.01^{\mathrm{ef}}$ & $<0.01^{\mathrm{ef}}$ & $0.01^{\mathrm{ef}}$ & $0.02^{\mathrm{f}}$ & $<0.01^{\mathrm{ef}}$ & $<0.01^{\mathrm{ef}}<$ & $<0.01^{\mathrm{ef}}$ & $<0.01^{\mathrm{ef}}$ & $0.01^{\mathrm{ef}}$ & $<0.01^{\mathrm{ef}}$ & $<0.01^{\mathrm{ef}}$ & $<0.01^{\mathrm{ef}}$ & $\mathrm{f}<0.01^{\mathrm{ef}}$ & $<<0.01^{\mathrm{ef}}$ & \multirow{2}{*}{$38.96^{c}$} & \multirow{2}{*}{48.81} & \multirow{2}{*}{$69.72^{\mathrm{c}}$} \\
\hline & $<0.01^{\mathrm{ef}}$ & $<0.01^{\mathrm{ef}}$ & $\mathrm{f}^{\mathrm{s}}<0.01^{\mathrm{ef}}$ & $0.02^{\mathrm{f}}$ & $0.03^{\mathrm{f}}$ & $0.01^{\text {ef }}$ & $<0.01^{\text {ef }}$ & $0.01^{\mathrm{ef}}$ & $<0.01^{\mathrm{ef}}$ & $0.03^{\mathrm{f}}$ & $0.01^{\mathrm{ef}}$ & $<0.01^{\mathrm{ef}}$ & $0.01^{\text {ef }}$ & $<0.01^{\text {ef }}$ & $0.01^{\mathrm{ef}}$ & & & \\
\hline \multirow{2}{*}{ Hexanal } & 0.70 & 4.33 & 2.74 & 1.26 & 2.23 & 0.92 & 0.43 & 2.26 & 0.60 & 0.45 & 0.62 & 0.51 & 0.79 & 0.80 & 1.53 & \multirow{2}{*}{$23.04^{\mathrm{c}}$} & & \\
\hline & 1.35 & 7.47 & 4.04 & 2.36 & 3.42 & 1.60 & 1.01 & 4.13 & 1.28 & 0.80 & 1.05 & 1.54 & 1.03 & 1.14 & 3.29 & & 25.83 & $53.8-x$ \\
\hline & $0.01^{\mathrm{f}}$ & $0.02^{\mathrm{f}}$ & 0.04 & 0.20 & 2.56 & 0.14 & 0.12 & 0.13 & 0.05 & 0.12 & 0.56 & $0.02^{\mathrm{f}}$ & 0.21 & 0.05 & 0.38 & & & \\
\hline 3-Methyl-1-butanol & $0.02^{\mathrm{f}}$ & 0.05 & 0.07 & 0.40 & 2.84 & 0.37 & 0.24 & 0.22 & 0.12 & 0.26 & 0.76 & 0.04 & 0.37 & 0.06 & 0.83 & 25. & 64. & 41. \\
\hline & 9.02 & 11.01 & 0.84 & 6.48 & 2.20 & 5.21 & 3.72 & 3.32 & 3.05 & 1.90 & 1.42 & 9.38 & 2.09 & 22.73 & 18.16 & & & \\
\hline$(E)-2-\mathrm{H}$ & 16.98 & 16.83 & 1.53 & 9.34 & 4.65 & 7.71 & 6.01 & 4.81 & 4.74 & 2.82 & 2.57 & 15.93 & 3.31 & 43.32 & 23.85 & 19. & 23. & 46. \\
\hline & $<0.01^{\mathrm{ef}}$ & 0.23 & 1.56 & 0.63 & 0.09 & 0.20 & 2.59 & 1.16 & 2.78 & 1.15 & 0.17 & 0.62 & 0.20 & 1.78 & 0.09 & & & \\
\hline exenyl acetate & $0.01^{\mathrm{f}}$ & 0.39 & 2.70 & 0.77 & 1.08 & 3.07 & 4.56 & 1.80 & 5.19 & 1.55 & 0.27 & 0.90 & 0.29 & 3.03 & 0.21 & 19. & 30. & 62. \\
\hline & 0.05 & 0.21 & $0.04^{\mathrm{f}}$ & 0.07 & 0.27 & $0.01^{\mathrm{ef}}$ & $0.02^{\mathrm{f}}$ & 0.16 & $0.02^{\mathrm{f}}$ & $0.02^{\mathrm{f}}$ & $0.02^{\mathrm{f}}$ & $0.01^{\mathrm{ef}}$ & 0.07 & $0.03^{\mathrm{f}}$ & 0.13 & & & \\
\hline (E)-2-Heptenal & 0.10 & 0.40 & 0.20 & 0.17 & 0.73 & 0.07 & 0.26 & 0.48 & 0.14 & 0.05 & 0.07 & 0.05 & 0.53 & 0.17 & 0.34 & 24. & 03. & 30. \\
\hline & $0.01^{\mathrm{ef}}$ & 0.28 & 0.16 & $0.02^{\mathrm{f}}$ & 0.24 & $0.01^{\mathrm{ef}}$ & $<0.01^{\mathrm{ef}}$ & 0.24 & $0.02^{\mathrm{f}}$ & $0.02^{\mathrm{f}}$ & 0.09 & $<0.01^{\mathrm{ef}}$ & 0.26 & $0.01^{\mathrm{ef}}$ & $0.03^{\mathrm{f}}$ & & & \\
\hline 6-Methyl-5-hepten-2-one & $0.04^{\mathrm{f}}$ & 0.39 & 0.36 & $0.04^{\mathrm{f}}$ & 0.78 & $0.05^{\mathrm{f}}$ & $0.03^{\mathrm{f}}$ & 0.50 & 0.08 & 0.07 & 0.54 & $0.03^{\mathrm{f}}$ & 0.79 & 0.06 & 0.16 & 43.20 & $65.10^{00}$ & $61.64^{4}$ \\
\hline & 0.14 & 0.27 & 1.33 & 0.61 & 1.65 & 1.72 & 1.10 & 0.68 & 0.36 & 1.01 & 0.21 & 0.42 & 1.84 & 0.80 & 1.03 & $1326^{b c}$ & & $5006^{\mathrm{cd}}$ \\
\hline 1-Hexanol & 0.30 & 0.89 & 2.72 & 0.82 & 2.01 & 2.46 & 1.54 & 0.69 & 0.53 & 1.24 & 0.32 & 0.94 & 4.15 & 1.54 & 1.21 & 13.2 & $2 \%$ & 59.96 \\
\hline & 0.59 & 0.76 & 0.48 & 0.15 & 5.29 & 0.12 & $0.03^{\mathrm{f}}$ & 2.83 & 0.26 & 0.11 & 0.36 & $0.07^{\mathrm{f}}$ & 0.48 & $0.03^{\mathrm{f}}$ & 0.46 & & & \\
\hline Nonanal & 1.54 & 4.80 & 1.75 & 1.53 & 8.65 & 1.17 & 0.94 & 5.41 & 0.83 & 1.57 & 0.94 & 0.35 & 1.36 & 0.58 & 2.52 & 46. & & 53.70 \\
\hline & $0.01^{\mathrm{f}}$ & 0.03 & $0.02^{\mathrm{f}}$ & $0.01^{\mathrm{f}}$ & 0.06 & $0.01^{\mathrm{f}}$ & $<0.01^{\mathrm{ef}}$ & 0.03 & $<0.01^{\mathrm{ef}}$ & $<0.01^{\mathrm{ef}}$ & $0.02^{\mathrm{f}}$ & $<0.01^{\mathrm{ef}}$ & $0.02^{\mathrm{f}}$ & $<0.01^{\mathrm{ef}}$ & $0.02^{\mathrm{f}}$ & & $3887-2$ & 6407 \\
\hline 1-Octen-3-ol & $0.01^{\mathrm{f}}$ & 0.05 & 0.03 & $0.02^{\mathrm{f}}$ & 0.18 & $0.01^{\mathrm{f}}$ & $0.01^{\mathrm{f}}$ & 0.05 & $0.01^{\mathrm{f}}$ & $0.01^{\mathrm{f}}$ & 0.03 & $<0.01^{\text {ef }}$ & 0.04 & $0.01^{\mathrm{f}}$ & 0.07 & 31.48 & 38.8 & 64.07 \\
\hline & 0.06 & 0.05 & $0.03^{\mathrm{f}}$ & $0.02^{\mathrm{f}}$ & $0.01^{\mathrm{f}}$ & $0.03^{\mathrm{f}}$ & $0.03^{\mathrm{f}}$ & $0.02^{\mathrm{f}}$ & 0.06 & 0.12 & $0.01^{\mathrm{f}}$ & 0.14 & 0.04 & 0.27 & 0.08 & & & \\
\hline$(E, E)-2,4$-Hexadienal & 0.58 & 0.62 & 0.14 & 0.31 & 0.53 & 0.51 & 0.25 & 0.20 & 0.83 & 0.46 & 0.06 & 1.16 & 0.12 & 1.20 & 1.03 & 63.46 & 69.0 & 105.4 \\
\hline & 0.19 & 1.20 & 0.30 & 2.46 & 3.94 & 9.63 & 0.79 & 0.89 & 0.37 & 3.99 & 0.62 & 0.27 & 0.38 & 0.42 & 0.26 & & & \\
\hline Acetic acid & 0.45 & 3.67 & 0.62 & 6.52 & 8.95 & 25.06 & 1.98 & 2.12 & 0.62 & 12.75 & 1.68 & 0.58 & 0.84 & 0.75 & 0.72 & 17.4 & 2.0 & 71.83 \\
\hline & 0.39 & 1.80 & 0.37 & 0.46 & 0.05 & 0.04 & $<0.01^{\mathrm{ef}}$ & 0.22 & $<0.01^{\mathrm{ef}}$ & 0.22 & $<0.01^{\mathrm{ef}}$ & $0.01^{\mathrm{f}}$ & 0.03 & $0.01^{\mathrm{f}}$ & 0.12 & & & \\
\hline Propanoic acid & 0.70 & 2.93 & 0.82 & 0.92 & 0.17 & 0.11 & 0.03 & 0.44 & 0.07 & 0.44 & 0.07 & 0.06 & 0.15 & 0.10 & 0.33 & & & \\
\hline
\end{tabular}


Table cont.

\begin{tabular}{|c|c|c|c|c|c|c|c|c|c|c|c|c|c|c|c|c|c|c|}
\hline (E)-2-Decenal & $\begin{array}{l}0.25^{f} \\
0.98\end{array}$ & $\begin{array}{c}0.02^{\mathrm{ef}} \\
1.09\end{array}$ & $\begin{array}{c}0.04^{\mathrm{ef}} \\
0.28^{\mathrm{f}}\end{array}$ & $\begin{array}{l}0.08^{\text {ef }} \\
0.14^{\text {ef }}\end{array}$ & $\begin{array}{l}0.49^{f} \\
3.57\end{array}$ & $\begin{array}{l}0.10^{\text {ef }} \\
0.13^{\text {ef }}\end{array}$ & $\begin{array}{l}0.03^{\mathrm{ef}} \\
0.06^{\mathrm{ef}}\end{array}$ & $\begin{array}{l}0.30^{f} \\
2.26\end{array}$ & $\begin{array}{l}0.04^{\mathrm{ef}} \\
0.06^{\mathrm{ef}}\end{array}$ & $\begin{array}{l}0.08^{\mathrm{ef}} \\
0.25^{\mathrm{f}}\end{array}$ & $\begin{array}{l}0.04^{\text {ef }} \\
0.09^{\text {ef }}\end{array}$ & $\begin{array}{l}0.03^{\mathrm{ef}} \\
0.03^{\mathrm{ef}}\end{array}$ & $\begin{array}{c}0.01^{\mathrm{ef}} \\
2.14\end{array}$ & $\begin{array}{l}0.09^{\mathrm{ef}} \\
0.09^{\mathrm{ef}}\end{array}$ & $\begin{array}{l}0.20 \\
1.18\end{array}$ & $36.65^{\mathrm{c}}$ & 54.33 & $61.52^{\mathrm{c}}$ \\
\hline & 0.85 & 0.22 & $0.02^{\mathrm{ef}}$ & $0.08^{f}$ & $0.05^{f}$ & $0.03^{\mathrm{ef}}$ & $0.01^{\mathrm{ef}}$ & $0.02^{e f}$ & $<0.01^{\mathrm{ef}}$ & $0.11^{\mathrm{f}}$ & $0.01^{\text {ef }}$ & $<0.01^{\mathrm{ef}}$ & $<0.01^{\text {ef }}$ & $0.01^{\text {ef }}$ & $0.01^{\mathrm{ef}}$ & \multirow{2}{*}{$27.11^{\mathrm{b}}$} & \multirow{2}{*}{$57.61^{\mathrm{bd}}$} & \multirow{2}{*}{$25.51^{\mathrm{d}}$} \\
\hline Pentanoic acid & 2.08 & 0.48 & 0.18 & 0.22 & $0.13^{f}$ & $0.09^{f}$ & $0.01^{\text {ef }}$ & $0.09^{f}$ & $0.04^{\mathrm{ef}}$ & 0.18 & $0.02^{\text {ef }}$ & $0.05^{f}$ & $0.06 f$ & $0.02^{\mathrm{ef}}$ & $0.04^{\mathrm{ef}}$ & & & \\
\hline
\end{tabular}

${ }^{a}$ Relative Standard Deviation (\%) calculated as mean of RSD\% for each compound among the involved labs by removing outliers.

${ }^{\mathrm{b}} \mathrm{RSD} \%$ values obtained for QM1 and QM2 showed significant differences $(\mathrm{p}<0.05)$.

${ }^{\mathrm{c}} \mathrm{RSD} \%$ values obtained for QM1 and QM3 showed significant differences $(\mathrm{p}<0.05)$.

${ }^{\mathrm{d}} \mathrm{RSD} \%$ values obtained for QM2 and QM3 showed significant differences $(\mathrm{p}<0.05)$.

e Concentration is below the LOD (Table 7).

${ }^{\mathrm{f}}$ Concentration is below the LOQ (Table 8). 
Table 6. Mean and standard deviation values of recovery $\left(\mathrm{R}_{\mathrm{ap}}\right)$ calculated from the results of the labs involved using the three types of quantification methods (QMs). The recovery values are shown when the entire concentration range and low concentration range were applied in the calibration curves.

\begin{tabular}{|c|c|c|c|c|c|c|}
\hline \multirow{2}{*}{ Volatile compounds } & \multicolumn{3}{|c|}{$\begin{array}{c}\text { Whole concentration range } \\
(0.05-10.00 / 25.00 \mathrm{mg} / \mathrm{kg})^{\mathrm{a}}\end{array}$} & \multicolumn{3}{|c|}{$\begin{array}{c}\text { Low concentration range } \\
(0.05-2.5 \mathrm{mg} / \mathrm{kg}) \\
\end{array}$} \\
\hline & QM1 & QM2 & QM3 & QM1 & QM2 & QM3 \\
\hline Octane & $92 \pm 21$ & $90 \pm 42$ & $135 \pm 123$ & $93 \pm 28$ & $68 \pm 38^{c}$ & $117 \pm 82$ \\
\hline Ethyl acetate & $99 \pm 22$ & $94 \pm 46$ & $118 \pm 79$ & $74 \pm 10^{\mathrm{c}}$ & $54 \pm 31^{c}$ & $94 \pm 28$ \\
\hline Ethanol & $104 \pm 67$ & $131 \pm 80$ & $138 \pm 104$ & $71 \pm 39$ & $71 \pm 45$ & $108 \pm 85$ \\
\hline Ethyl propanoate & $101 \pm 18$ & $96 \pm 44$ & $128 \pm 87$ & $86 \pm 12$ & $64 \pm 37^{c}$ & $103 \pm 39$ \\
\hline Hexanal & $106 \pm 11$ & $150 \pm 67$ & $266 \pm 221$ & $119 \pm 42$ & $114 \pm 53$ & $188 \pm 142$ \\
\hline 3-Methyl-1-butanol & $100 \pm 9$ & $93 \pm 35$ & $139 \pm 106$ & $94 \pm 13$ & $68 \pm 39$ & $108 \pm 33$ \\
\hline E-2-Hexenal & $88 \pm 9$ & $118 \pm 37$ & $224 \pm 152$ & $144 \pm 63$ & $129 \pm 55$ & $223 \pm 167$ \\
\hline (Z)-3-Hexenyl acetate & $88 \pm 5$ & $121 \pm 54$ & $248 \pm 180$ & $159 \pm 82$ & $139 \pm 60$ & $267 \pm 227$ \\
\hline (E)-2-Heptenal & $102 \pm 25$ & $92 \pm 21$ & $157 \pm 96$ & $152 \pm 56$ & $92 \pm 23$ & $180 \pm 139$ \\
\hline 6-Methyl-5-hepten-2-one & $105 \pm 28$ & $94 \pm 21$ & $163 \pm 97$ & $154 \pm 59$ & $93 \pm 22$ & $181 \pm 131$ \\
\hline 1-Hexanol & $100 \pm 7$ & $140 \pm 69$ & $269 \pm 206$ & $143 \pm 58$ & $135 \pm 69$ & $238 \pm 202$ \\
\hline Nonanal & $82 \pm 16$ & $107 \pm 26$ & $224 \pm 140$ & $155 \pm 74$ & $136 \pm 54$ & $247 \pm 195$ \\
\hline 1-Octen-3-ol & $86 \pm 8$ & $121 \pm 53$ & $252 \pm 175$ & $166 \pm 80$ & $147 \pm 63$ & $283 \pm 246$ \\
\hline$(E, E)-2,4-H e x a d i e n a l$ & $95 \pm 13$ & $89 \pm 25$ & $147 \pm 102$ & $148 \pm 54$ & $90 \pm 22$ & $180 \pm 146$ \\
\hline Acetic acid & $84 \pm 26$ & $105 \pm 11$ & $208 \pm 146$ & $125 \pm 72$ & $115 \pm 72$ & $157 \pm 104$ \\
\hline Propanoic acid & $94 \pm 25$ & $88 \pm 37$ & $119 \pm 44$ & $111 \pm 26$ & $76 \pm 36^{c}$ & $115 \pm 26$ \\
\hline (E)-2-Decenal & $72 \pm 21$ & $71 \pm 32$ & $109 \pm 29^{b}$ & $158 \pm 34^{\mathrm{c}}$ & $110 \pm 53^{c}$ & $160 \pm 126$ \\
\hline Pentanoic acid & $99 \pm 16$ & $92 \pm 22$ & $184 \pm 172$ & $184 \pm 87$ & $114 \pm 47$ & $223 \pm 250$ \\
\hline
\end{tabular}


Table 7. Mean values of LOD (mg/kg) for each VOC by applying four calculation methods; the ranges are also shown in parentheses for the first three methods.

\begin{tabular}{lcccc}
\hline Volatile Compounds & Calculation Method & Calculation Method & Calculation Method & Calculation Method \\
$\mathbf{1}$ & $0.64(0.18-0.89)$ & $0.23(0.06-0.31)$ & $0.72(0.06-1.27)$ & 0.01 \\
\hline Octane & $0.44(0.42-0.48)$ & $0.19(0.17-0.24)$ & $0.43(0.17-0.68)$ & 0.03 \\
Ethyl acetate & $1.29(1.07-1.56)$ & $0.45(0.38-0.55)$ & $0.54(0.51-0.58)$ & 0.03 \\
Ethanol & $0.25(0.17-0.30)$ & $0.10(0.07-0.12)$ & $0.22(0.07-0.49)$ & 0.02 \\
Ethyl propanoate & $1.69(1.42-2.13)$ & $0.53(0.45-0.67)$ & $1.43(0.22-2.50)$ & 0.02 \\
Hexanal & $0.62(0.38-0.84)$ & $0.22(0.13-0.29)$ & $0.62(0.29-0.90)$ & 0.01 \\
3-Methyl-1-butanol & $0.96(0.07-1.64)$ & $0.38(0.03-0.64)$ & $0.13(0.05-0.27)$ & 0.01 \\
(E)-2-Hexenal & $1.00(0.17-1.73)$ & $0.39(0.06-0.68)$ & $0.15(0.07-0.30)$ & 0.01 \\
(Z)-3-Hexenyl acetate & $0.92(0.34-1.48)$ & $0.32(0.12-0.52)$ & $0.16(0.16-0.16)$ & 0.02 \\
(E)-2-Heptenal & $1.12(0.72-1.55)$ & $0.39(0.25-0.54)$ & $0.18(0.10-0.24)$ & 0.02 \\
6-Methyl-5-hepten-2-one & $0.03(0.47-1.18)$ & 0.01 \\
1-Hexanol & $1.69(0.73-2.22)$ & $0.53(0.23-0.70)$ & 0.93 \\
Nonanal & $1.33(0.21-2.09)$ & $0.52(0.08-0.83)$ & $0.50(0.10-0.76)$ & 0.03 \\
1-Octen-3-ol & $1.58(0.57-2.47)$ & $0.53(0.19-0.83)$ & $0.52(0.25-0.69)$ & 0.01 \\
(E,E)-2,4-Hexadienal & $0.87(0.34-1.73)$ & $0.31(0.12-0.61)$ & $0.12(0.08-0.17)$ & 0.01 \\
Acetic acid & $1.83(0.85-2.63)$ & $0.59(0.28-0.85)$ & $0.92(0.59-1.18)$ & 0.01 \\
Propanoic acid & $0.58(0.27-1.18)$ & $0.20(0.10-0.41)$ & $0.36(0.11-0.51)$ & 0.01 \\
(E)-2-Decenal & $1.60(1.19-2.40)$ & $0.56(0.42-0.84)$ & $0.57(0.41-0.68)$ & 0.18 \\
Pentanoic acid & $0.98(0.31-1.42)$ & $0.34(0.11-0.50)$ & $0.19(0.14-0.25)$ & 0.05 \\
\hline Ne: -a: not aid & & &
\end{tabular}

Note: n/a: not available as not detectable. 
Table 8. Mean values of the LOQ ( $\mathrm{mg} / \mathrm{kg}$ ) for each volatile compound by applying four calculation methods; the ranges are shown in parentheses for the first three methods.

\begin{tabular}{|c|c|c|c|c|}
\hline Volatile Compounds & $\begin{array}{c}\text { Calculation Method } \\
1 \\
\end{array}$ & $\begin{array}{c}\text { Calculation Method } \\
2 \\
\end{array}$ & $\begin{array}{c}\text { Calculation Method } \\
\mathbf{3} \\
\end{array}$ & $\begin{array}{c}\text { Calculation Method } \\
4\end{array}$ \\
\hline Octane & $1.95(0.56-2.69)$ & $0.68(0.20-0.95)$ & $2.18(0.19-3.85)$ & 0.03 \\
\hline Ethyl acetate & $1.35(1.26-1.45)$ & $0.58(0.50-0.73)$ & $1.31(0.52-2.07)$ & 0.08 \\
\hline Ethanol & $3.91(3.24-4.72)$ & $1.38(1.14-1.65)$ & $1.64(1.54-1.74)$ & 0.09 \\
\hline Ethyl propanoate & $0.74(0.52-0.92)$ & $0.30(0.21-0.37)$ & $0.67(0.20-1.47)$ & 0.07 \\
\hline Hexanal & $5.11(4.30-6.46)$ & $1.62(1.37-2.04)$ & $4.34(0.68-7.58)$ & 0.07 \\
\hline 3-Methyl-1-butanol & $1.89(1.14-2.55)$ & $0.66(0.40-0.89)$ & $1.89(0.87-2.72)$ & 0.04 \\
\hline (E)-2-Hexenal & $2.90(0.22-4.97)$ & $1.14(0.09-1.95)$ & $0.38(0.15-0.82)$ & 0.03 \\
\hline (Z)-3-Hexenyl acetate & $3.03(0.50-5.24)$ & $1.20(0.19-2.06)$ & $0.46(0.21-0.91)$ & 0.02 \\
\hline (E)-2-Heptenal & $2.79(1.04-4.48)$ & $0.97(0.36-1.57)$ & $0.48(0.47-0.49)$ & 0.05 \\
\hline 6-Methyl-5-hepten-2-one & $3.41(2.19-4.70)$ & $1.19(0.77-1.64)$ & $0.55(0.30-0.74)$ & 0.06 \\
\hline 1-Hexanol & $5.11(2.23-6.73)$ & $1.62(0.70-2.13)$ & $2.82(1.42-3.59)$ & 0.01 \\
\hline Nonanal & $4.02(0.65-6.33)$ & $1.58(0.25-2.50)$ & $1.52(0.30-2.31)$ & 0.09 \\
\hline 1-Octen-3-ol & $4.80(1.73-7.47)$ & $1.61(0.58-2.52)$ & $1.57(0.76-2.09)$ & 0.03 \\
\hline$(E, E)-2,4-H e x a d i e n a l$ & $2.65(1.03-5.25)$ & $0.93(0.36-1.84)$ & $0.37(0.25-0.51)$ & 0.04 \\
\hline Acetic acid & $5.53(2.58-7.98)$ & $1.79(0.84-2.58)$ & $2.79(1.78-3.57)$ & 0.04 \\
\hline Propanoic acid & $1.75(0.82-3.57)$ & $0.61(0.29-1.25)$ & $1.11(0.34-1.54)$ & 0.02 \\
\hline (E)-2-Decenal & $4.85(3.62-7.28)$ & $1.69(1.27-2.54)$ & $1.72(1.24-2.07)$ & 0.53 \\
\hline Pentanoic acid & $2.96(0.94-4.29)$ & $1.03(0.33-1.50)$ & $0.59(0.43-0.76)$ & 0.15 \\
\hline
\end{tabular}

Note: n/a: not available as not detectable. 


\section{Lampante olive oil}

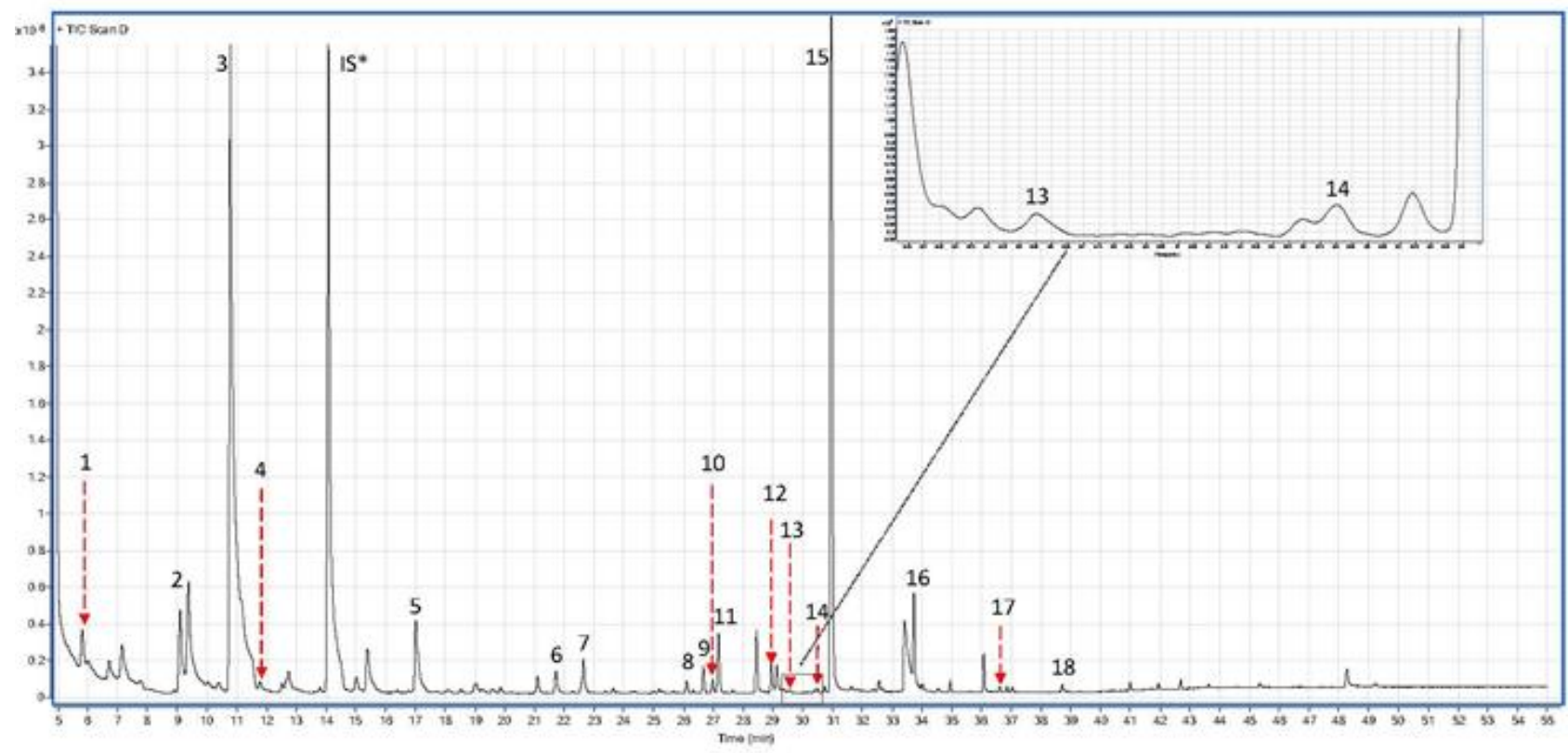

\section{Virgin olive oil}

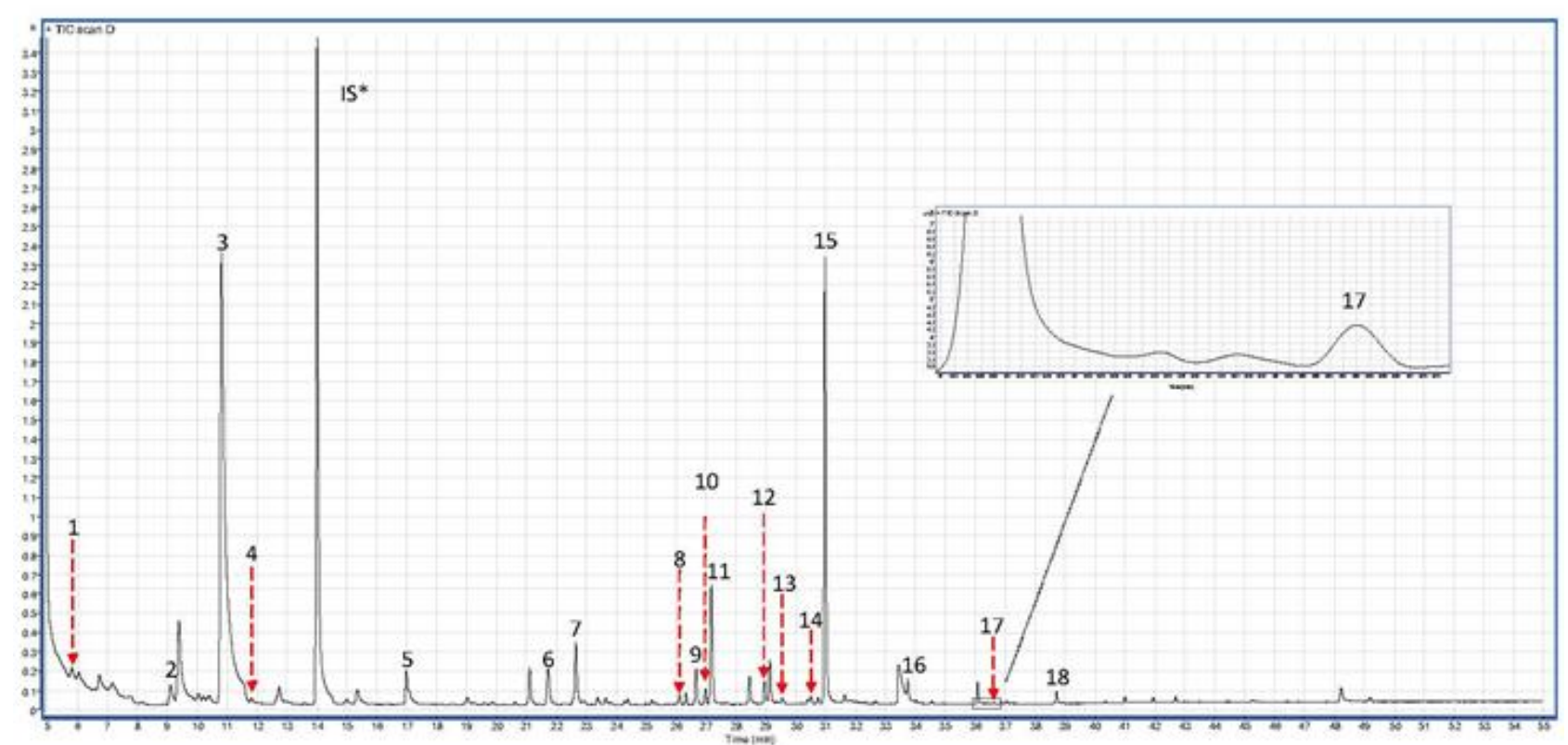

Figure 1. Chromatogram of volatile compounds of a lampante olive oil and a virgin olive analyzed by SPME-GC-MS. The correspondence of the codes with the volatile compounds is shown in Table 1. 


\section{FIGURE 2}

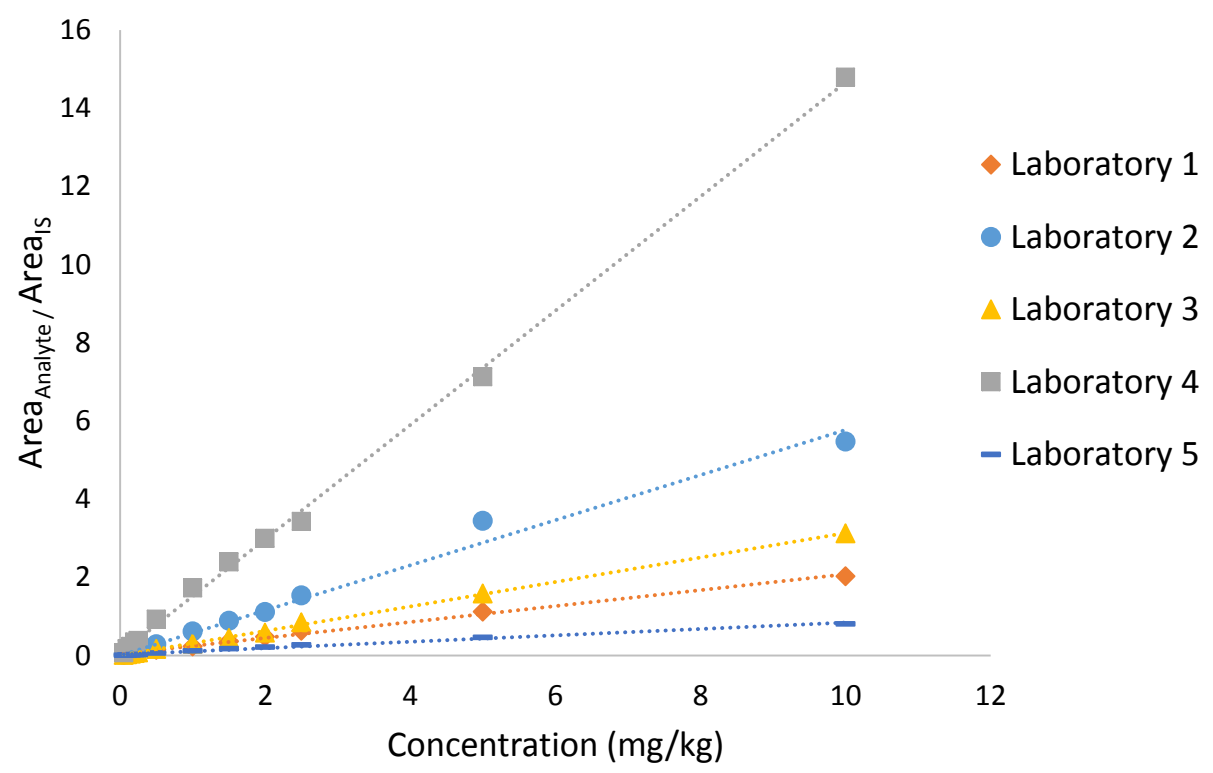

Figure 2. Calibration curves of ethyl propanoate for quantification method 2 (QM2). 


\section{SUPPLEMENTARY INFORMATION}

Collaborative validation trial of a harmonized SPME-GC-MS method for analysis of selected volatile compounds in virgin olive oils

Ramón Aparicio-Ruiz ${ }^{1}$, Clemente Ortiz Romero ${ }^{1}$, Diego L. García González ${ }^{1}$, Maurizio Servili ${ }^{2}$, Roberto Selvaggini ${ }^{2}$, Florence Lacoste ${ }^{3}$, Julien Escobessa ${ }^{3}$, Stefania Vichi ${ }^{4}$, Beatriz QuintanillaCasas $^{4}$, Pierre Alain Golay ${ }^{5}$, Paolo Lucci ${ }^{6}$, Erica Moret $^{6}$, Enrico Valli $^{7}$, Alessandra Bendini ${ }^{7}$, Tullia Gallina Toschi ${ }^{7}$ 


\section{Ethyl propanoate}
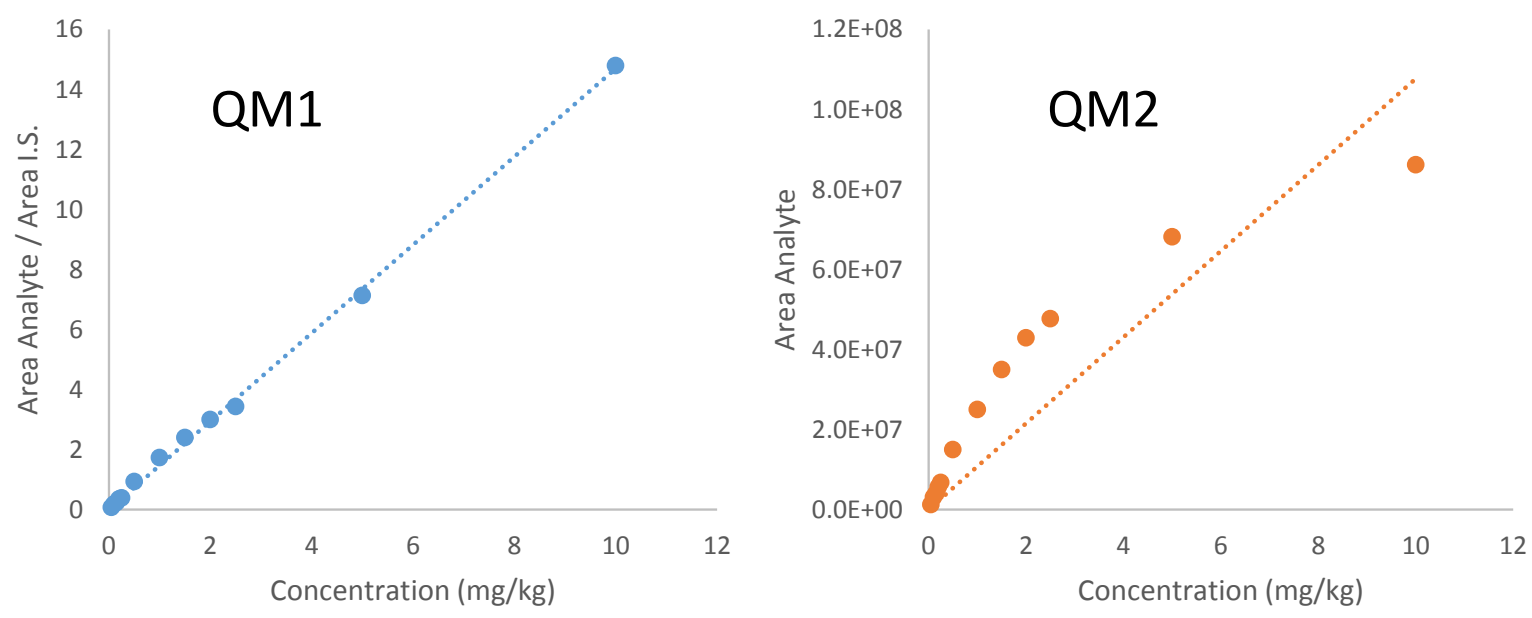

(E,E)-2,4-Hexadienal
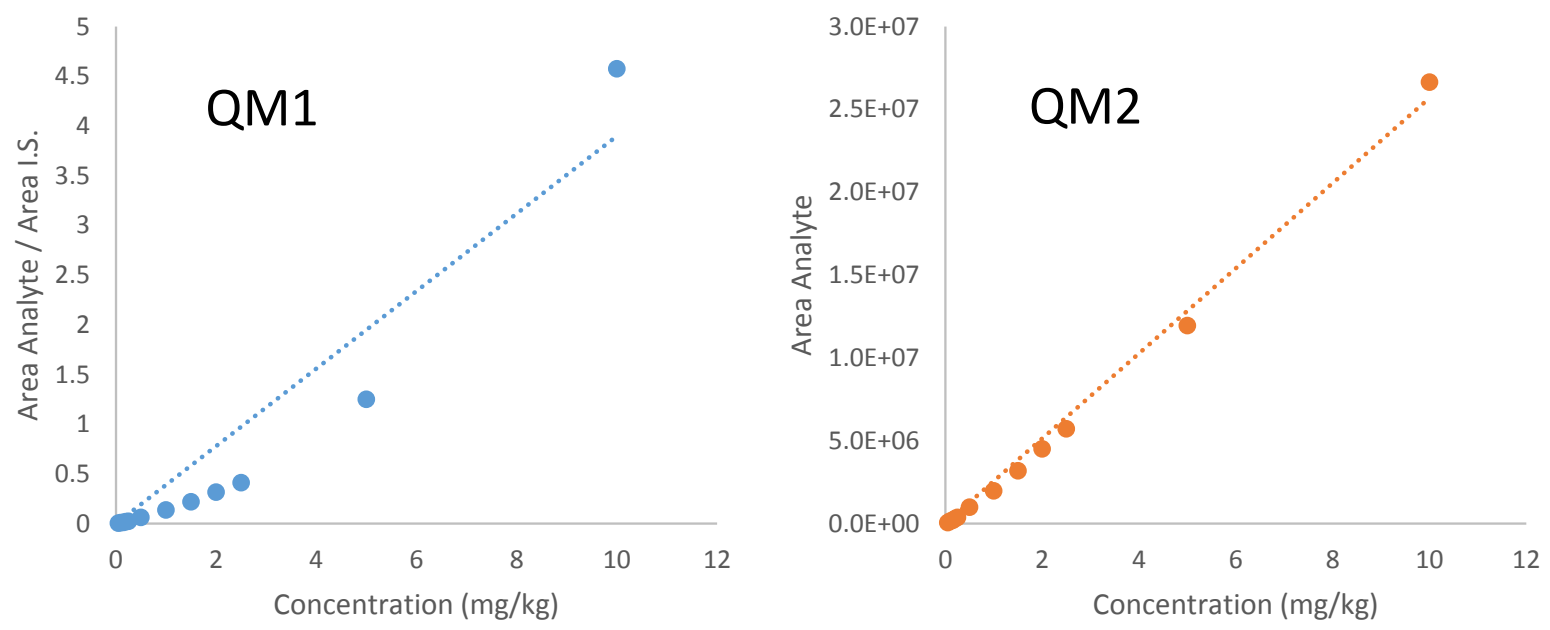

Figure S1. Calibration curves of ethyl propanoate and $(E, E)-2,4$,hexadienal built in quantification methods 1 and 2 (QM1, QM2). 
Table S2. Slope and typical error (mean \pm standard deviation) of the regression equation built for the calibration curves (QM1).

\begin{tabular}{lcc}
\hline Volatile compounds & Slope (Mean \pm SD) & Typical error (Mean \pm SD) \\
\hline Octane & $0.201 \pm 0.186$ & $0.052 \pm 0.066$ \\
Ethyl acetate & $0.666 \pm 0.655$ & $0.231 \pm 0.238$ \\
Ethanol & $0.159 \pm 0.136$ & $0.184 \pm 0.163$ \\
Ethyl propanoate & $0.508 \pm 0.552$ & $0.067 \pm 0.035$ \\
Hexanal & $0.099 \pm 0.089$ & $0.064 \pm 0.045$ \\
3-Methyl-1-butanol & $0.091 \pm 0.057$ & $0.022 \pm 0.016$ \\
(E)-2-Hexenal & $0.064 \pm 0.047$ & $0.053 \pm 0.043$ \\
(Z)-3-Hexenyl acetate & $0.072 \pm 0.064$ & $0.068 \pm 0.070$ \\
(E)-2-Heptenal & $0.037 \pm 0.030$ & $0.024 \pm 0.030$ \\
6-Methyl-5-hepten-2-one & $0.036 \pm 0.026$ & $0.023 \pm 0.024$ \\
1-Hexanol & $0.092 \pm 0.046$ & $0.085 \pm 0.069$ \\
Nonanal & $0.004 \pm 0.003$ & $0.006 \pm 0.005$ \\
1-Octen-3-ol & $0.073 \pm 0.044$ & $0.108 \pm 0.104$ \\
(E,E)-2,4-Hexadienal & $0.073 \pm 0.061$ & $0.044 \pm 0.038$ \\
Acetic acid & $0.135 \pm 0.080$ & $0.112 \pm 0.079$ \\
Propanoic acid & $0.052 \pm 0.028$ & $0.022 \pm 0.024$ \\
(E)-2-Decenal & $0.002 \pm 0.002$ & $0.002 \pm 0.003$ \\
Pentanoic acid & $0.058 \pm 0.034$ & $0.041 \pm 0.041$ \\
\hline
\end{tabular}

Table S3. Linearity in the low concentration range of the calibration curve $(0.05-0.25 \mathrm{mg} / \mathrm{kg})(\mathrm{QM} 1)$.

\begin{tabular}{lccc}
\hline \multicolumn{1}{c}{ Volatile compound } & $\mathbf{R}^{\mathbf{2}}$ & Slope & Intercept \\
\hline Octane & $0.972 \pm 0.030$ & $0.152 \pm 0.101$ & $0.002 \pm 0.003$ \\
Ethyl acetate & $0.978 \pm 0.026$ & $0.959 \pm 0.979$ & $0.004 \pm 0.007$ \\
Ethanol & $0.963 \pm 0.051$ & $0.246 \pm 0.240$ & $-0.003 \pm 0.014$ \\
Ethyl propanoate & $0.975 \pm 0.034$ & $0.532 \pm 0.543$ & $0.002 \pm 0.004$ \\
Hexanal & $0.964 \pm 0.034$ & $0.093 \pm 0.075$ & $0.001 \pm 0.002$ \\
3-Methyl-1-butanol & $0.969 \pm 0.030$ & $0.112 \pm 0.076$ & $-0.001 \pm 0.001$ \\
(E)-2-Hexenal & $0.941 \pm 0.107$ & $0.044 \pm 0.040$ & $-0.001 \pm 0.001$ \\
(Z)-3-Hexenyl acetate & $0.987 \pm 0.009$ & $0.055 \pm 0.063$ & $-0.001 \pm 0.001$ \\
(E)-2-Heptenal & $0.984 \pm 0.021$ & $0.017 \pm 0.009$ & $0.000 \pm 0.000$ \\
6-Methyl-5-hepten-2-one & $0.980 \pm 0.018$ & $0.019 \pm 0.011$ & $0.000 \pm 0.000$ \\
1-Hexanol & $0.979 \pm 0.028$ & $0.065 \pm 0.042$ & $0.000 \pm 0.000$ \\
Nonanal & $0.613 \pm 0.436$ & $0.001 \pm 0.000$ & $0.001 \pm 0.001$ \\
1-Octen-3-ol & $0.976 \pm 0.020$ & $0.039 \pm 0.028$ & $-0.033 \pm 0.058$ \\
(E,E)-2,4-Hexadienal & $0.986 \pm 0.019$ & $0.051 \pm 0.034$ & $-0.001 \pm 0.001$ \\
Acetic acid & $0.977 \pm 0.019$ & $0.132 \pm 0.089$ & $0.014 \pm 0.018$ \\
Propanoic acid & $0.975 \pm 0.021$ & $0.044 \pm 0.031$ & $0.000 \pm 0.001$ \\
(E)-2-Decenal & $0.629 \pm 0.431$ & $0.000 \pm 0.000$ & $0.000 \pm 0.000$ \\
Pentanoic acid & $0.908 \pm 0.109$ & $0.020 \pm 0.014$ & $0.001 \pm 0.001$ \\
\hline
\end{tabular}



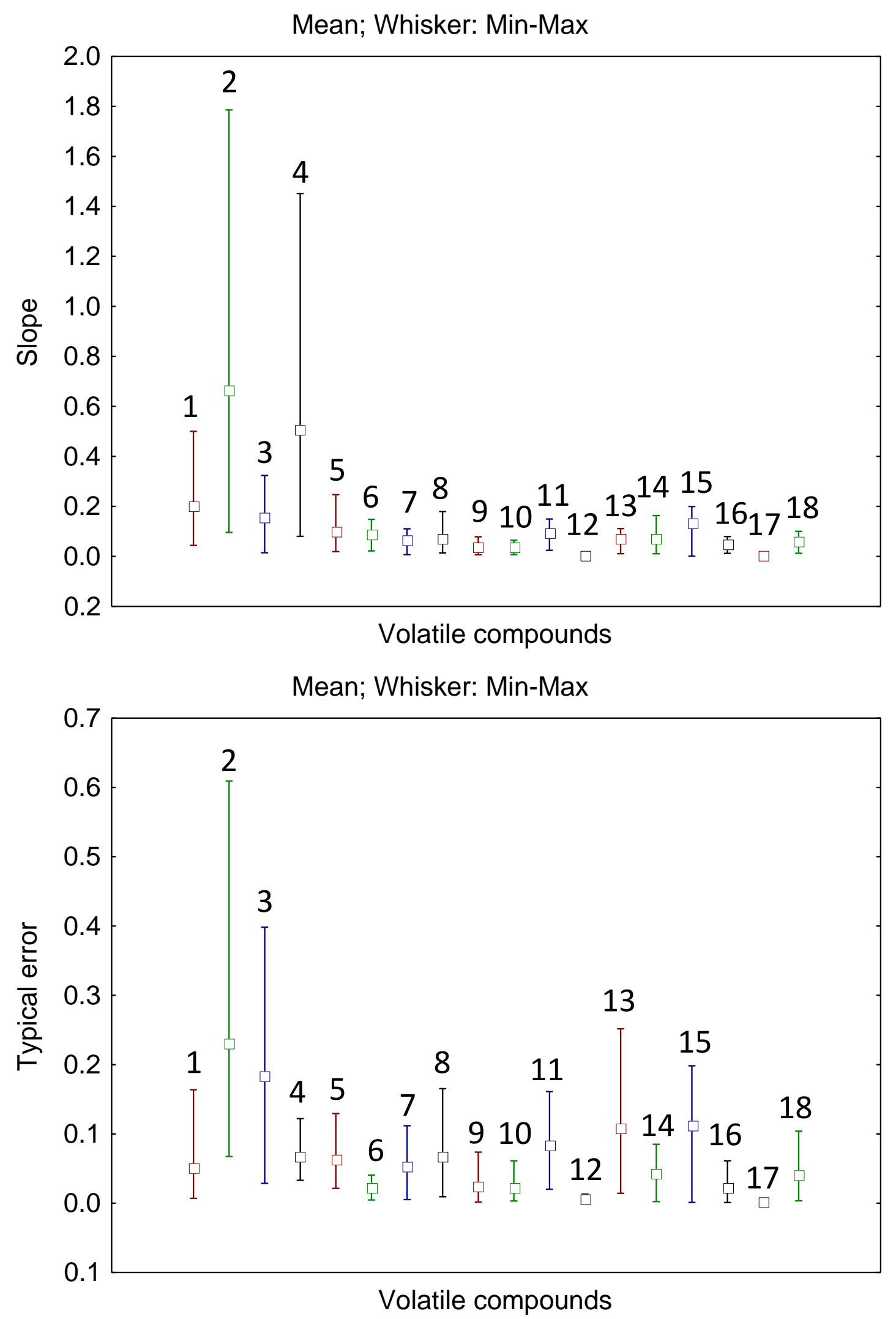

Figure S2. Box and whisker plots of the slope and typical error (mean \pm standard deviation) of the regression equation built for the calibration curves (QM1). The volatile compound codes correspond to Table 1. 


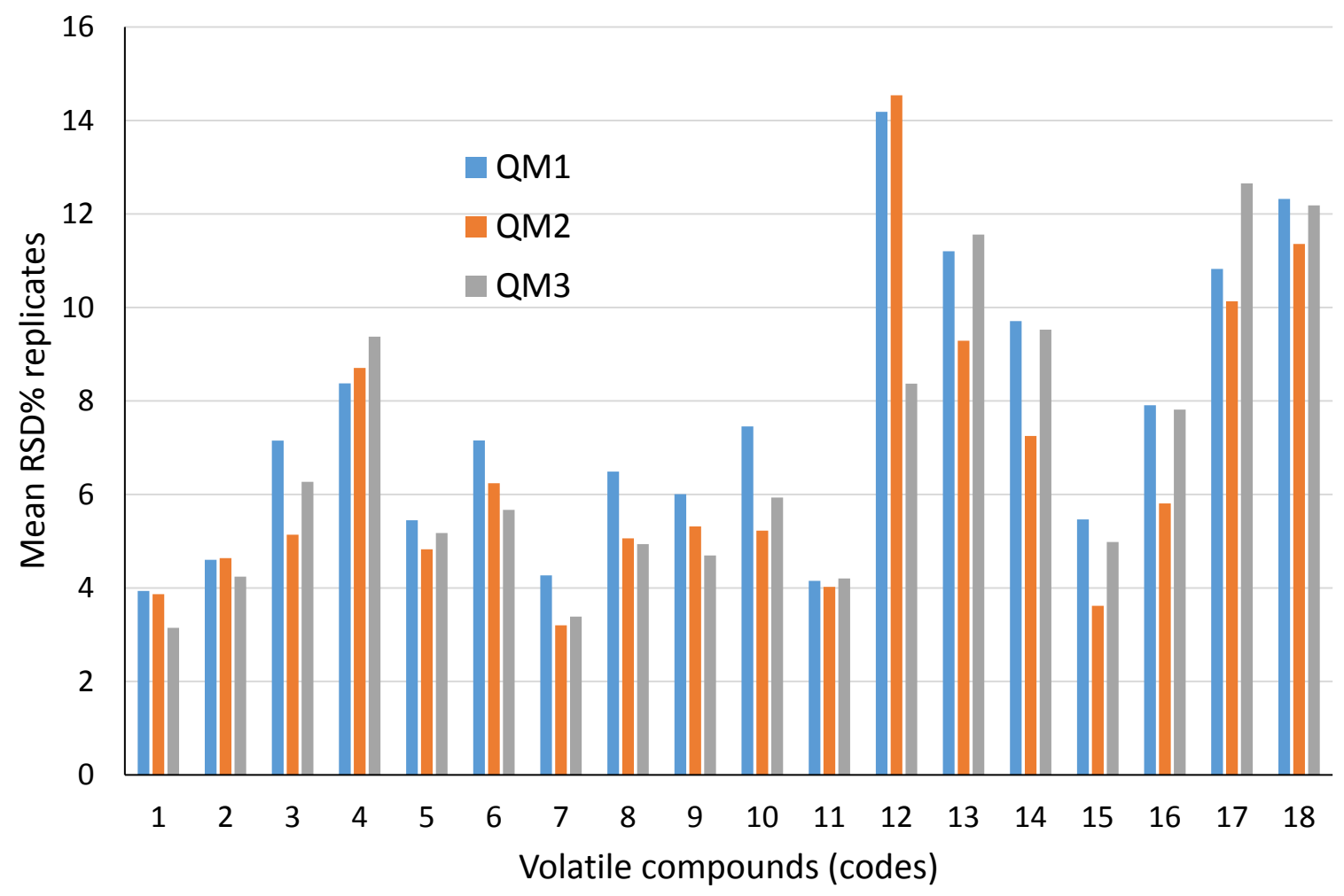

Figure S3. Mean relative standard deviation (RSD\%) computed from the duplicates of the 15 samples analyzed by the 5 laboratories. The volatile compound codes correspond to Table 1 . 


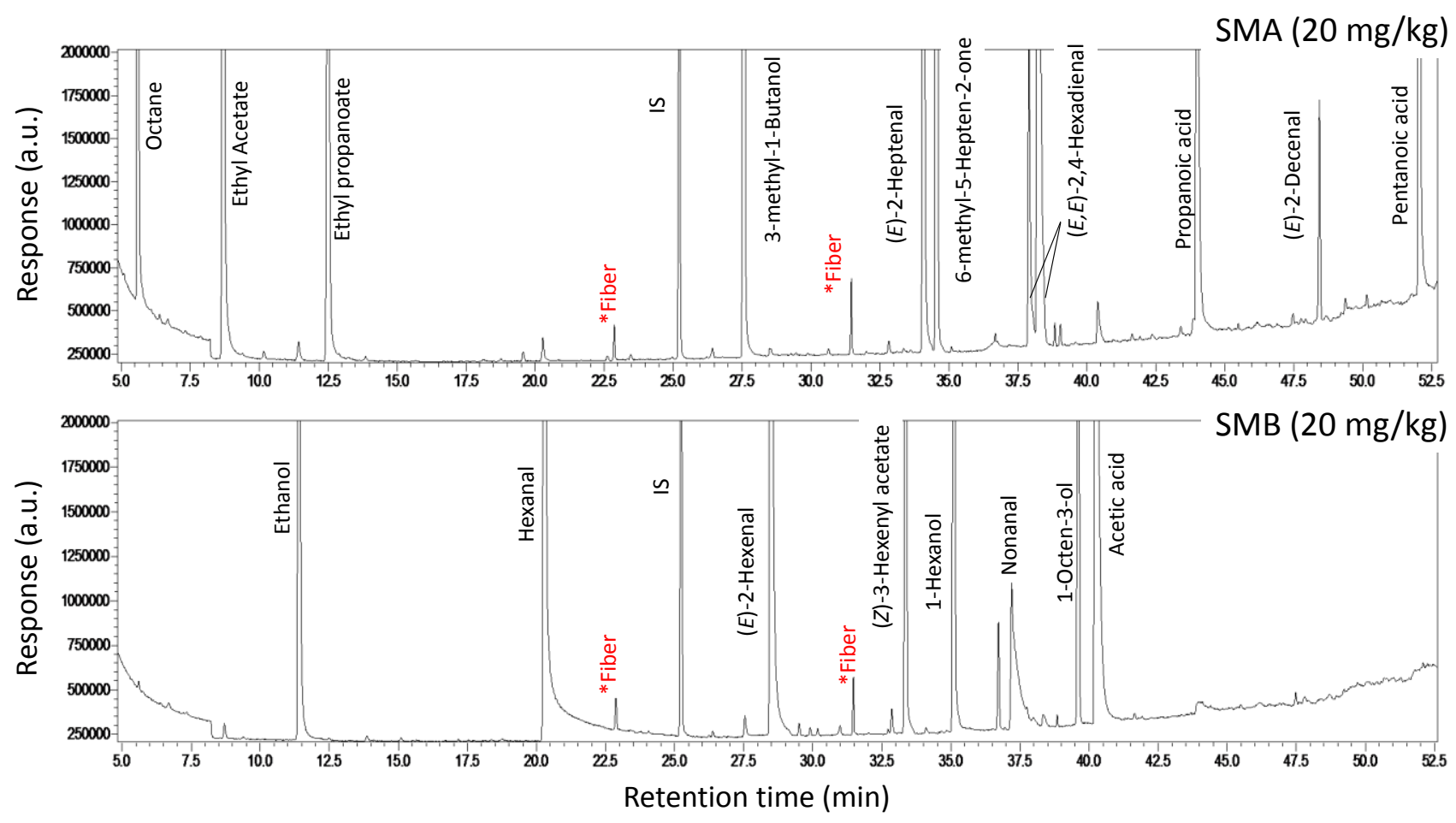

Figure S4. Chromatograms of the standard mixtures SMA and SMB built for calibration (calibration point $20 \mathrm{mg} / \mathrm{kg}$ ). Note: *Compounds deriving from the SPME divinylbenzene/carboxen/polydimethylsiloxane (DVB/CAR/PDMS) fiber. 


\section{Collaborative peer validation of a harmonized SPME-GC-MS method for analysis of selected volatile compounds in virgin olive oils}

Ramón Aparicio-Ruiz, Clemente Ortiz Romero, Enrico Casadei, Diego L. García González, Maurizio Servili, Roberto Selvaggini, Florence Lacoste, Julien Escobessa, Stefania Vichi, Beatriz

Quintanilla-Casas, Pierre Alain Golay, Paolo Lucci, Erica Moret, Enrico Valli, Alessandra Bendini, Tullia Gallina Toschi

\section{Highlights:}

- A SPME-GC-MS based protocol with 3 possible quantification methods was developed.

- A peer-interlab study was carried out (5 labs, 18 volatiles, 15 virgin olive oils).

- Results were compared with a similar study carried with FID detector.

- Linearity, recovery, precision and repeatability were satisfactory.

- Three compounds showed reproducibility RSD >40\%, partially due to high LOQs. 


\section{Declaration of interests}

$\bigotimes$ The authors declare that they have no known competing financial interests or personal relationships that could have appeared to influence the work reported in this paper.

$\square$ The authors declare the following financial interests/personal relationships which may be considered as potential competing interests: 


\section{Lampante olive oil}

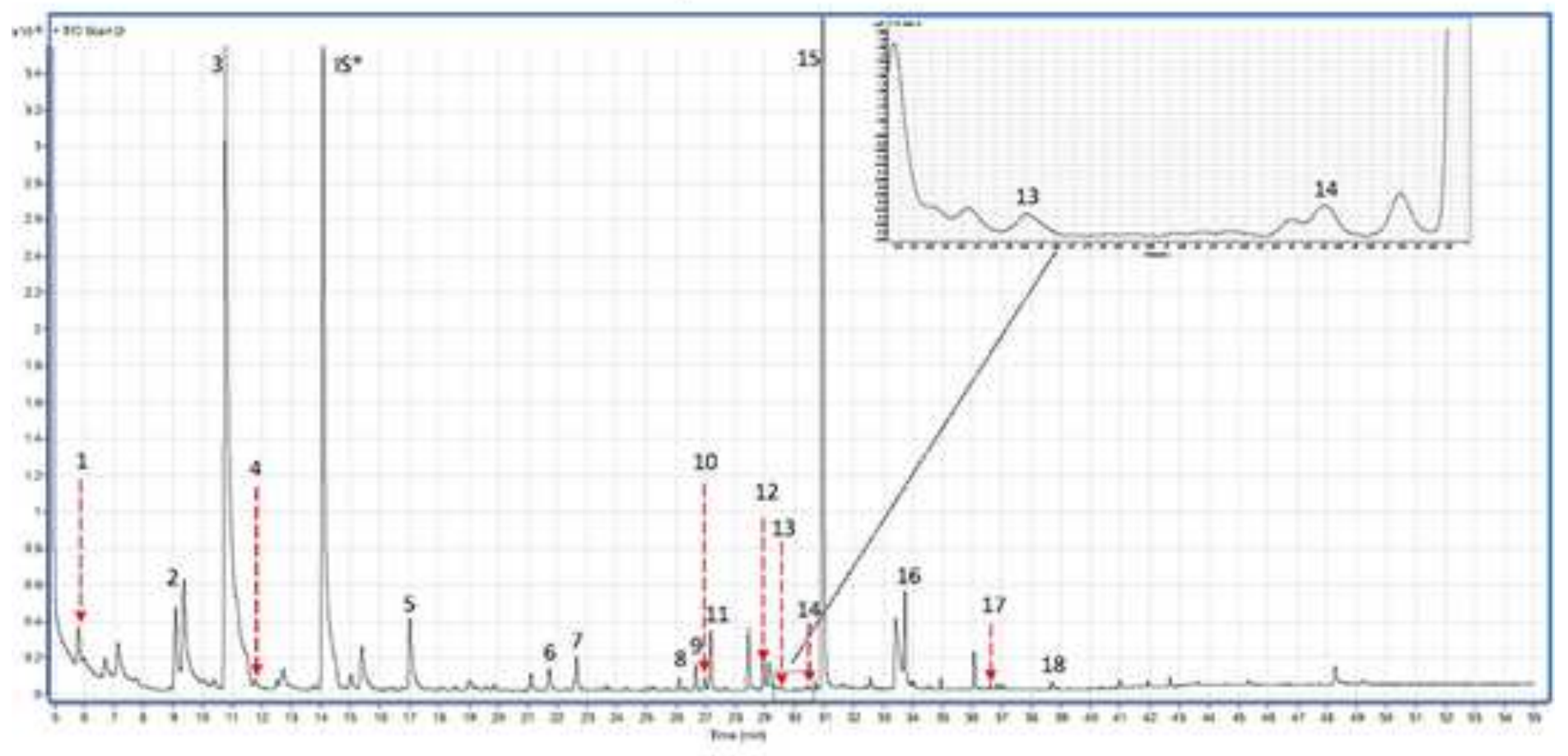

\section{Virgin olive oil}

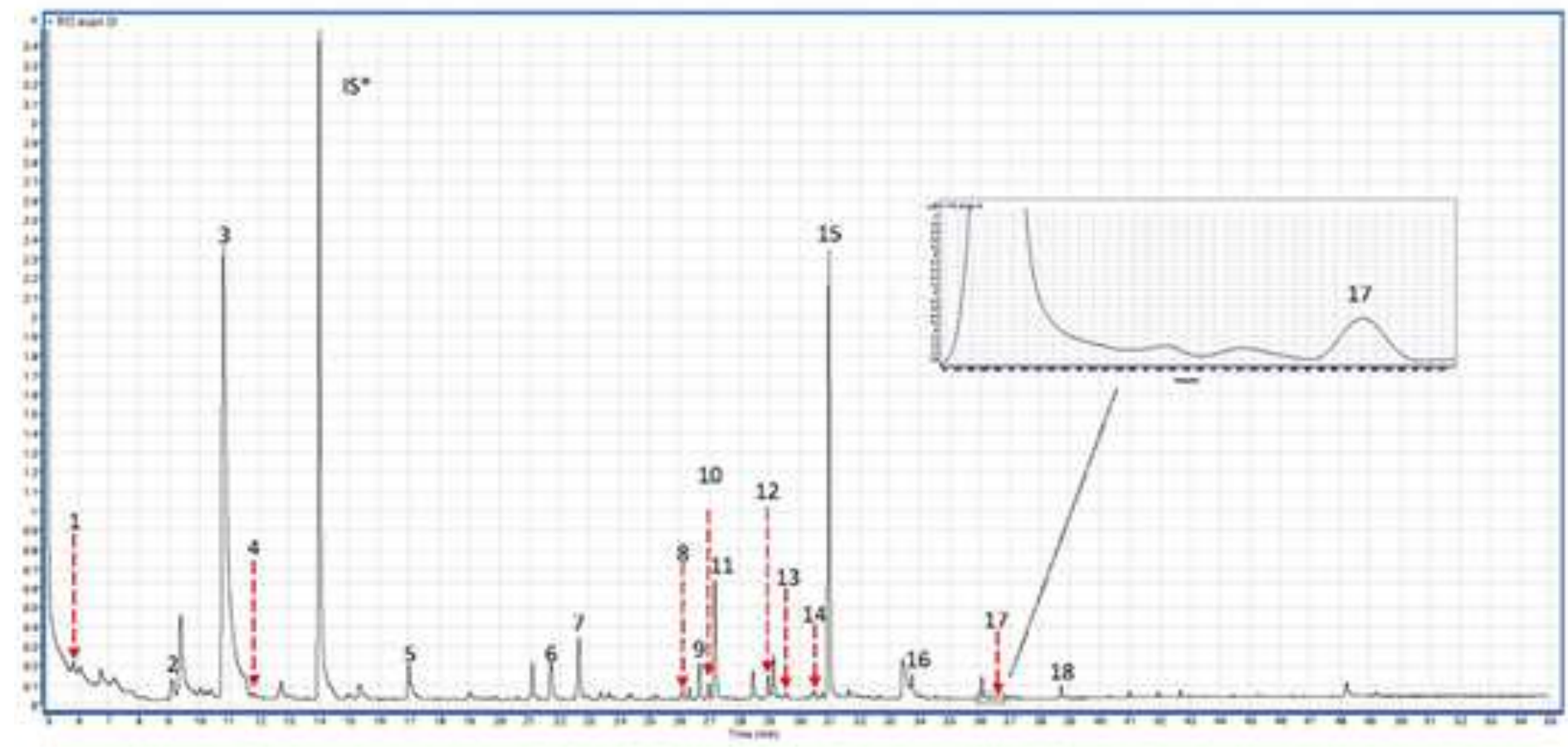




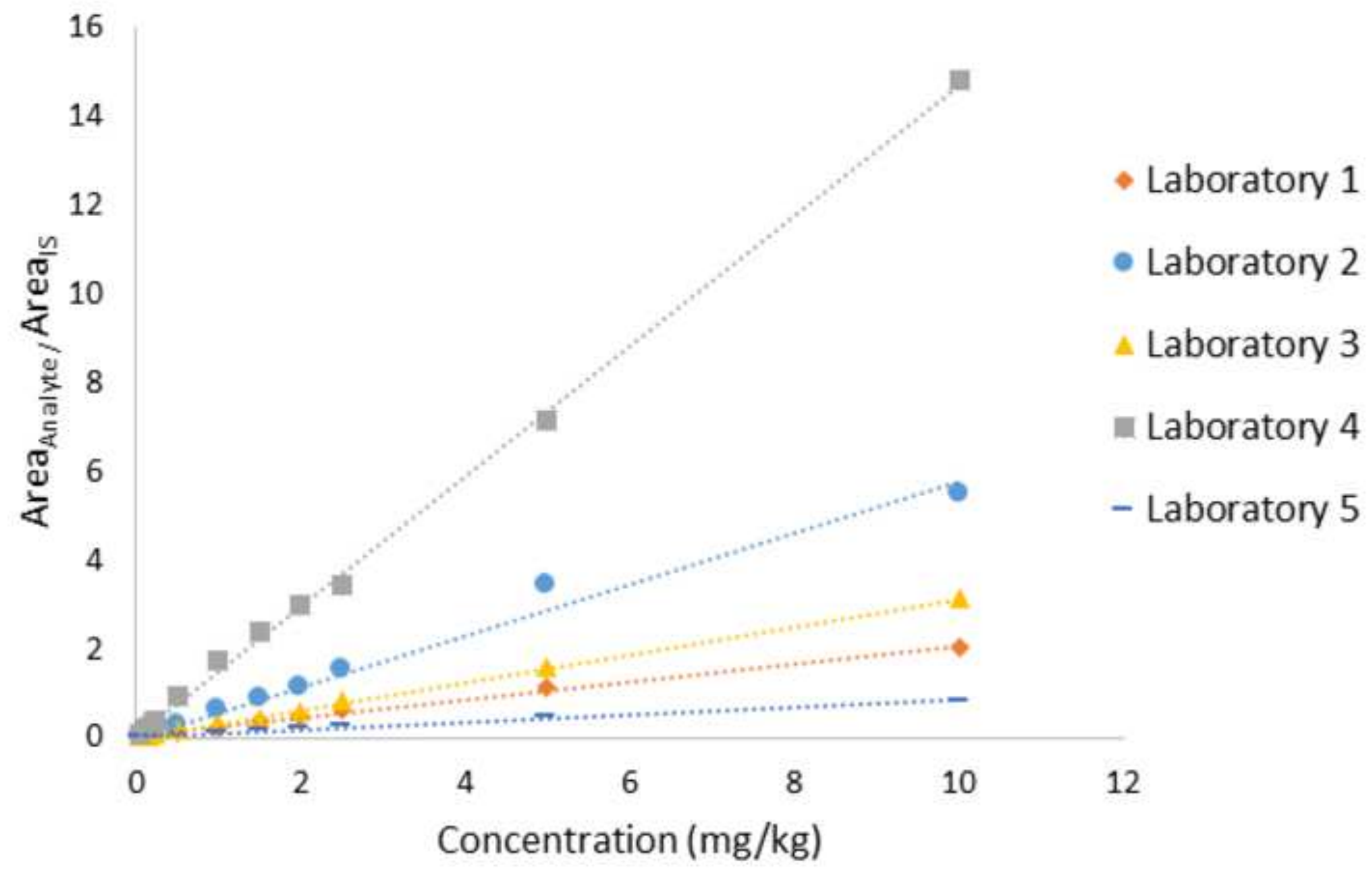


Click here to access/download Method Details (MethodsX) MethodsX_Aparicio Ruiz et al..docx 